\title{
El proyecto urbano como experiencia colectiva, colaborativa, situada, perfomática y transdisciplinar
}

\author{
The urban project as a collective, collaborative, situated, \\ performative and transdisciplinary experience
}

\author{
Luciana Lima1 y Verónica Pastuszuk² \\ Fecha de recepción: 26-01-2021 - Fecha de aceptación: 09-05-2021 \\ Hábitat y Sociedad (ISSN 2173-125X), n. ${ }^{\circ}$ 14, noviembre de 2021, pp. 159-183. \\ https://doi.org/10.12795/HabitatySociedad.2021.i14.09
}

\section{Summary}

The city we inhabit, the territory we share, it is nowadays under revision, and urbanism is central to these reflections. The experiences of "Territorio Tolosa" (Tolosa Territory), a collective project of urban contemplation and neighborhood transformation, comprised by architects, artists and the local community, which I have coordinated for the past five years. We have run walks around Tolosa, organized workshops, performances and different types of collective practices to re-signify the spaces we inhabit. Our research questions those architectures that support hegemonic ways of producing controlled and a priori spaces, proposing instead open processes to participatory practices, which include walks and collective mapping as ways of thinking about urbanism. In one hand, we want to explore procedures to deconstruct the traditional ways of producing architecture, based on individual skill, in order to promote them as collective processes, collaborative and transdisciplinary. On the other hand, we want to explore deeper into the architectures of delay, proximity and care, to enhance the pre-existing urban landscape and the sensitive encounter between people. Tolosa is neighborhood in La Plata city, Buenos Aires, Argentina. Tolosa will be taken as the research focus, to rethink the neighborhood in the xxI century from feminist perspective.

\section{Key words}

Neighborhood; Collective; Collaborative; Transdisciplinary; Feminist Urbanism

\section{Resumen}

La ciudad que habitamos, el territorio en el que convivimos, están hoy en día siendo fuertemente revisados. Y el proyecto urbano es central en estas reflexiones. Las experiencias de Territorio Tolosa, un colectivo de contemplación urbana y transformación barrial, conformado por arquitectos, artistas y vecinos que coordinamos desde hace cinco años, son la base de estas investigaciones. Realizamos recorridos, talleres, performances y distintos tipos de prácticas colectivas para resignificar los espacios que habitamos. Esta investigación cuestiona aquellas arquitecturas que sostienen modos hegemónicos de producir espacios controlados y apriorísticos, proponiendo en cambio procesos proyectuales abiertos a ciertas prácticas participativas que incluyan recorridos y mapeos colectivos para abordar lo urbano. Por un lado, se busca explorar los procedimientos proyectuales que deconstruyan los modos tradicionales de producir arquitectura, basados en la destreza individual; en pos de propiciar el proyecto como un proceso colectivo, colaborativo y transdisciplinar. Y por otro lado profundizar en las arquitecturas de la demora, la proximidad y los cuidados, para potenciar el paisaje urbano preexistente y el encuentro sensible entre las personas. Se tomará como centro de la investigación, el barrio de Tolosa de la ciudad de La Plata, Argentina, para repensar el barrio en el siglo xxi desde miradas feministas.

\section{Pallabras clave}

Barrio; Colectivo; Colaborativo; Transdisciplinar; Urbanismo Feminista

1 Arquitecta Maestranda. Maestría en proyecto arquitectónico (MaPA), Facultad de Arquitectura, Diseño y Urbanismo, Universidad de Buenos Aires. Argentina (FADU-UBA). Participa en los siguientes proyectos: Territorio Tolosa, proyecto de transformación barrial (E-mail: territoriotolosa@gmail.com); La Ciudad Que Resiste, proyecto de investigación colectivo de urbanismo feminista; Proyecto de extensión, Arte género y espacio público (2018-2021), Facultad de Arquitectura y Urbanismo de La Plata, Argentina (FAU-UNLP). E-mail: lucianalima_78@hotmail.com. ORCID: https://orcid.org/0000-0003-2549-9322.

2 Arquitecta. Participa en los siguientes proyectos: Territorio Tolosa, proyecto de transformación barrial (E-mail: territoriotolosa@ gmail.com); La Ciudad Que Resiste, proyecto de investigación colectivo de urbanismo feminista. E-mail: veropastu@hotmail.com. ORCID: https://orcid.org/0000-0002-0159-5195. 


\section{Introducción}

La presente investigación ${ }^{3}$ busca indagar en dos objetivos principales que problematizan la arquitectura. Por un lado, profundizar en las arquitecturas de la demora, la proximidad y los cuidados. Y por otro lado explorar los procedimientos proyectuales que deconstruyan los modos tradicionales de producir arquitectura.

En primer lugar, abordaremos los modos de creación de espacios a partir de ciertas prácticas para experimentar el territorio siguiendo los conceptos de Francesco Careri, Jane Jacobs y el colectivo Punt 6. Francesco Careri (2016) propone modos desacelerados de uso del tiempo y del espacio, promoviendo el recorrido, y las derivas urbanas, como formas posibles de encuentro y de habitar los espacios que nos rodean. Jane Jacobs (1961) plantea el concepto de proximidad que refiere desarrollar las actividades cerca de la vivienda para intensificar la actividad social en el espacio público como espacio de encuentro y poder establecer lazos de confianza y de cuidado. Y, por último, el Col-Lectiu Punt 6 (2019) reflexiona sobre una arquitectura de los cuidados, basada en las redes de apoyo mutuo. Proponen un diseño del espacio público que ponga en el centro la vida de las personas. Se plantea también investigar sobre la creación del proyecto de arquitectura a partir de conocer sensiblemente el sitio a intervenir, sin arrasarlo ni colonizarlo, sino potenciando su singularidad. Esta búsqueda intenta contrarrestar la lógica de la ciudad neoliberal fragmentada y fracturada (Gorelik, 2004) que promueve la individualidad, la aceleración y la segregación como modos de vida urbana.

En segundo lugar, y en simultáneo, se abordará el otro gran eje de este trabajo, indagando en los procesos proyectuales a la manera de las arquitecturas participativas de los años sesenta y setenta que abordaron el proyecto como proceso colectivo. Como reflexiona Santiago Palero (2017) en su tesis dirigida por Ana Falú sobre arquitecturas participativas, es necesario dejar de concebir la arquitectura como si fuera una obra de arte acabada en sí misma, para entenderla como un proceso continuo y complejo, producto de la interacción de múltiples actores y agentes. Este proceso se propone como una construcción colectiva, colaborativa y transdisciplinar; un modo de proyectar que se construye desde ciertas prácticas que propicien la experiencia sensible del paisaje preexistente.

Nos interesa indagar en el potencial de las caminatas, el mapeo colectivo como metodologías para abordar el proyecto, dos polos de la experiencia del territorio (De Certeau, 1990).

Se tomará, como centro de todo el estudio, el barrio de Las Mil Casas $\left(1^{\circ}\right.$ barrio obrero de Latinoamérica creado por Emma de la Barra) y los galpones ferroviarios del siglo xix, del barrio de Tolosa, el barrio más antiguo de la ciudad de La Plata, Argentina. Estos predios hoy se encuentran degradados, en desuso o con usos parciales. Son territorios en resistencia al paso del tiempo, al avance de la ciudad, a la especulación. Allí rigen otras lógicas de organización diferentes a la trama urbana que lo rodea. Esa resistencia, será considerada como una oportunidad en espera para resignificar los espacios intersticiales y su nueva relación con el barrio y la ciudad (Ábalos y Herreros, 1997).

esta investigación contar con dos directores colaborativos, que trabajan en equipo, para profundizar en la propuesta de deconstruir roles tradicionales en arquitectura. 


\section{Abordajes}

¿Cómo construir nuevos discursos con diferentes valores si nos encontramos conformados por el patrón único de valores patriarcales masculinos hegemónicos disciplinares? (Muxi, 2018).

Esta investigación busca abordar esta pregunta que nos plantea Zaida Muxi focalizándose en dos aspectos principales. En primer lugar, se considera que la generación de las arquitecturas para la demora propiciará la experiencia sensible del territorio en resistencia. Aquellos proyectos que promuevan el andar en una deriva pausada, que en el recorrido genere rincones, desvíos, múltiples posibilidades, en el que se altere la circulación unidireccional cotidiana, propiciará la desaceleración en el movimiento para dar espacio al detenerse, reunirse y encontrarse. Esta puede producirse al potenciar y señalar las cualidades específicas del sitio, según el concepto de "atmósfera" de Peter Zumthor (2006); luz, expresión de los materiales, escala, intimidad, silencio. Estas cualidades de "atmósfera" definirán los sitios específicos donde detenerse según: el desgaste de los materiales con el paso del tiempo, la naturaleza indisciplinada, los paisajes sonoros, los usos en el predio, los espacios vacantes. Esto será recopilado colectivamente a través de las prácticas de caminatas y mapeos, generando información diversa y específica del sitio.

Consideramos también que los espacios que brindan hospitalidad, seguridad, alojamiento, refugio son los espacios que promueven la arquitectura de los cuidados. ${ }^{4}$

El segundo abordaje de esta investigación es sobre los procesos proyectuales colectivos y participativos.

Se considera que incorporar múltiples puntos de vista, deconstruye la idea de autoría y el rol jerárquico del arquitecto. Asimismo, incluir en el proceso ciertas prácticas como los recorridos urbanos y los mapeos colectivos, realizados por un grupo de vecinos, arquitectas, artistas, maestros, etc., genera un registro sensible y múltiple del territorio. Superponer esas nociones colectivas y específicas del territorio, genera la información para dar forma a los espacios. Dar forma es reinterpretar los datos, dar forma es dar sentido (Onfray, 2000). Esta será la tarea disciplinar de un grupo de arquitectas y arquitectos transdisciplinares, que reunirá los datos obtenidos por los mapeos para reinterpretarlos, redibujarlos y resignificarlos. Se considera que promover el rol colaborativo del arquitecto/a como una parte más del proceso genera responsabilidades compartidas. Además, la incorporación de prácticas colectivas contrarresta los proyectos totalizadores y apriorísticos en busca de proyectos más plurales y sensibles a las personas y los territorios preexistentes.

\section{Marco Teórico}

A continuación abordaremos el marco teórico desdoblado en los dos ejes principales de esta investigación.

\section{Modos de experimentar el territorio}

El territorio no es algo que está ahí esperando a ser descubierto y conquistado, sino eso que se hace al descubrir y conquistar (Deleuze, 1980). Siguiendo a Deleuze, el territorio es experiencia. Y es necesa-

4 Ver el apartado Marco Teórico donde se refiere a los cuidados. 
rio atravesar los espacios con el cuerpo para conocerlos y luego poder transformarlos. Por eso se propone pensar el espacio no como algo unilineal, controlado y definido a priori, ${ }^{5}$ sino pensar un espacio que genere recorridos, que propicie la desaceleración, para una experiencia holística del territorio. Para ello se propone desarrollar un concepto sobre los modos de percibir el espacio. De allí surge el concepto (re!) parar. ${ }^{6}$

Un concepto construido a partir de las experiencias de Territorio Tolosa, un colectivo de transformación barrial conformado por arquitectos, artistas y vecinos de Tolosa (de la ciudad de La Plata, Buenos Aires, Argentina) que coordino junto a Verónica Pastuszuk; y es el punto de partida de esta investigación que más adelante desarrollaremos.

(re!) parar es una herramienta de aproximación al territorio, un modo de experimentarlo sensiblemente, que sintetiza uno de los ejes de esta investigación: demora/proximidad/cuidados.

(re!) parar es demora. Es parar y desacelerarse para romper la lógica de la ciudad neoliberal que nos propone ir a toda velocidad para producir y consumir.

(re!) parar es proximidad. Es contemplar la ciudad y conocer a quienes nos rodean, nuestros vecinos. Una práctica relacional.

(re!) parar es cuidados. Es recomponer el encuentro entre las personas. Es cuidado mutuo y del territorio.

Se propone, a partir de ciertos autores, abordar algunos conceptos que expresen estas maneras de percibir el espacio. Por un lado, el arquitecto Francesco Careri, desde dos de sus escritos, Pasear, detenerse (2016) y Walkscapes, el andar como práctica estética (2013), plantea el caminar como metodología para contrarrestar la vida acelerada en la ciudad. Propone el concepto del andar contemplativo como lógica antiproductiva de resistencia. Por otro lado, Jorge Mario Jáuregui (2012) plantea extrañar la mirada para re-descubrir los espacios. Y así también Silvia Rivera Cusicanqui (2016) propone trabajar el sentido descolonizador de la mirada y convertirla en parte de una experiencia integral, que implique todos los sentidos. Ella plantea que un cambio en la percepción produciría un cambio en el diseño de espacios. Por último, Jane Jacobs (1961), urbanista de los años 60, propone el concepto de proximidad a través de intensificar la actividad social en el espacio público para establecer lazos de confianza y de cuidado mutuo. Para abordar el tema de los cuidados tomamos los conceptos de Johanna Hedva (2015), que plantea cuidar a otra persona como una manifestación anticapitalista e históricamente feminizada e invisibilizada.

En ese mismo sentido, Zaida Muxi (2019) nos propone el concepto de urbanismo feminista para re-pensar el espacio público de manera cooperativa, colaborativa, basadas en las redes de apoyo mutuo y en la democratización de los cuidados, en contraposición al modo hegemónico de producir espacios basadas en la autonomía y el individualismo, donde el parámetro de diseño ha sido el hombre, blanco, cis, heterosexual, y donde históricamente las mujeres y las disidencias hemos sido invisibilizadas (Moisset, 2015).

Por último, en este apartado que aborda los modos de percibir el territorio, queremos introducir el concepto de "territorio en resistencia". Es aquel espacio que tiene una estabilidad en tensión, que necesita de la no-intervención, no-control para existir. También un territorio en resistencia es un espacio intersticial que por distintas razones han quedado vacantes, sin uso o degradados. Tomamos el concepto de Áreas de impu-

5 A priori: antes e independientemente de la experiencia.

6 En Argentina, el agregado de la partícula RE aumenta la admiración hacia la persona hacia la cual se refiere el hablante. nidad de Ábalos y Herreros (1997), que plantea acerca de los espacios 
ambiguos entre espacio público y espacio natural como espacios abandonados, desregulados y, por eso, como una oportunidad en espera para su re-significación, para la apropiación imprevista y espontánea.

\section{El proyecto como proceso colectivo colaborativo y situado}

Proponemos pensar el proyecto a partir del concepto de "conocimiento situado" que nos plantea Donna Haraway (1991). Ningún conocimiento está desligado de su contexto, ni de la subjetividad de quien lo emite. Es necesario, dice Haraway, especificar desde qué punto de vista se parte. De esta manera se hace explícito el posicionamiento político, ya que los puntos de vista no son nunca neutros ni objetivos. Por eso el conocimiento siempre será parcial y situado. Tales conocimientos, situados y encarnados, parciales y limitados, provenientes de una pluralidad de sujetos cognoscentes; permite también, el diálogo interdisciplinario, multicultural y decolonial. Haraway (2019) propone la imagen de cuerdas (juego de niñas/niños) para reflexionar un modo de pensar/hacer o hacer-con, en lugar de autopoiesis, o autocreación; y aquí lo tomamos para pensar el proyecto de arquitectura y urbanismo; no como una imposición de ideas y conceptos hegemónicos y expertos, sino como un juego vincular de saberes, que busca la construcción colectiva, colaborativa y transdisciplinar desde conocimientos situados (Figura 1).

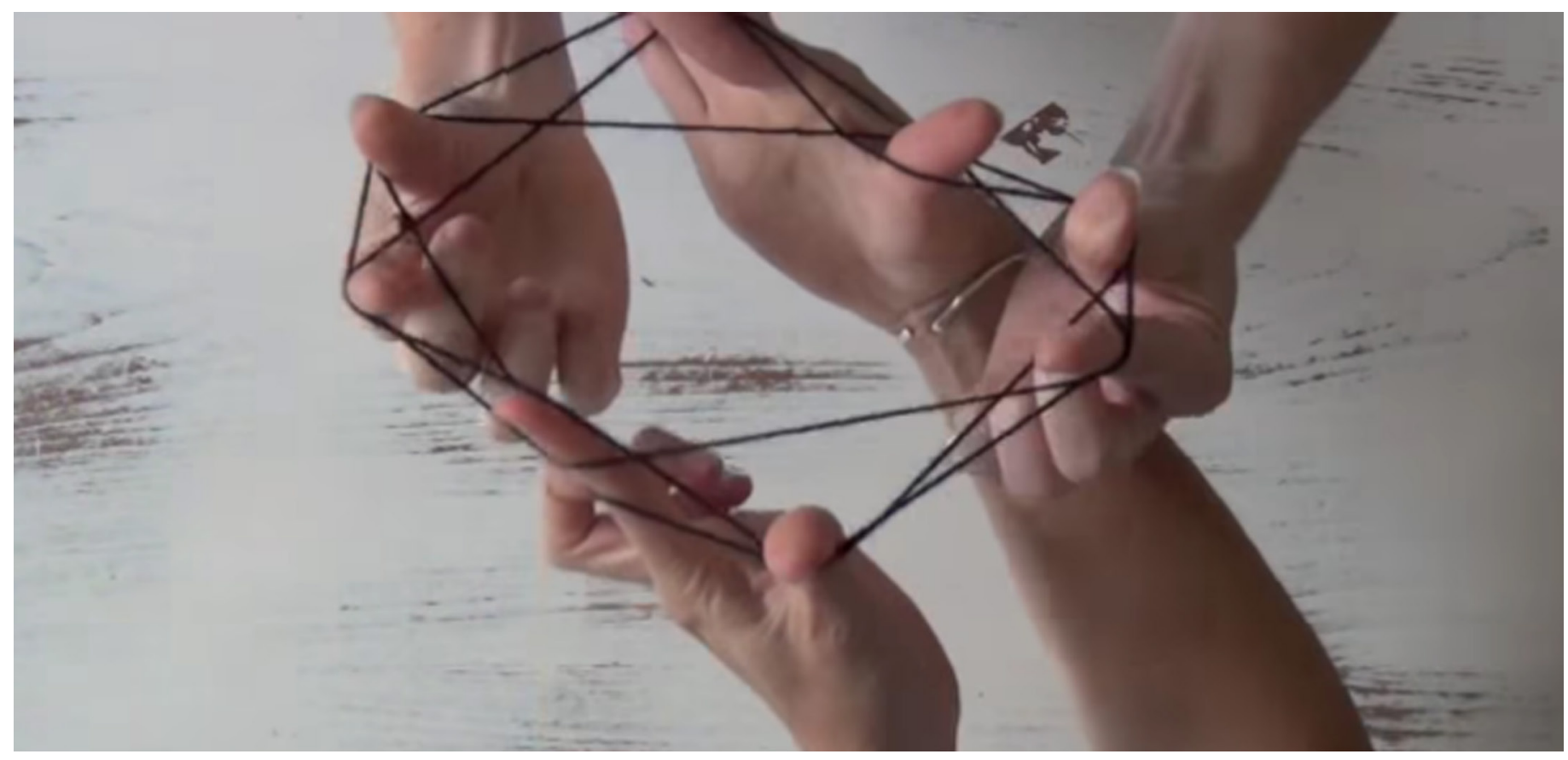

Es importante para este trabajo ubicar también históricamente los proyectos colectivos, este es el caso de las arquitecturas participativas, que John Habraken, John Turner y Christopher Alexander influenciaron en los sesenta y setenta, criticando al movimiento moderno, al rol jerárquico del arquitecto, a la construcción rígida y monótona de los grandes conjuntos de viviendas masivas de la posguerra europea. Estos referentes proponían a una arquitectura que pueda variar, transformarse en el tiempo generando paisajes diversos, oponiéndose a las ciudades pensadas para un hombre universal (Palero, 2017).
Figura 1: Figura de cuerdas. Fuente: Donna Haraway (2019). 
Para profundizar en las prácticas participativas y colectivas, se plantea aquí la contribución teórica que ciertas prácticas de experiencia sensible del territorio aportan al proceso proyectual como herramienta: el recorrido, el mapa, la deriva, la psicogeografía y el señalamiento.

En principio, M. De Certeau en su libro La Invención de lo cotidiano (1990) plantea la dialéctica entre el recorrido y el mapa. El recorrido es la experiencia sensorial y subjetiva del territorio. El plano, en cambio, es la visión totalizadora, la ciudad panorámica. La idea de mapa y recorrido también es abordada críticamente desde los conceptos de los situacionistas, cuestionando el modo de circular en la ciudad. Guy Debord promueve la teoría de la deriva en 1958 y las nociones de psicogeografía, planteando la experiencia del territorio como herramientas de trabajo (Navarro Luis, 1999). Otro modo de re-interpretar el territorio es el que plantea Alberto Greco (1962), que propone como práctica urbana el señalamiento, plasmado en el Manifiesto dito del arte vivo, que plantea visibilizar y hacer foco en lo que nos rodea cotidianamente. Por último, abordaremos el tema de las notaciones: registros, croquis, planos y mapeos colectivos, estos últimos proponen nuevas maneras de indagar sobre la representación. Seguimos las propuestas de S. Allen en el texto Mapeando lo inmapeable (2000), que propone abordar la complejidad del territorio repensando las convenciones de la representación, incorporando nuevas variables a los planos, que incluyan tiempo, cambio y puntos de vista múltiples.

\section{Estado de la cuestión}

Tomaremos cuatro casos desde los cuales partimos para pensar el proyecto y la ciudad como una experiencia colectiva y transdisciplinar, desde prácticas participativas y sensibles con el territorio. Nos interesa mencionar estas experiencias porque son el centro de esta investigación: los proyectos de recorridos y mapeos, los proyectos participativos y de autoconstrucción, de los que hemos sido parte.

Territorio Tolosa y La Ciudad Que Resiste son las colectivas que coordinamos. Y los proyectos Nuestras Arquitectas y a77 son coordinados por Inés Moisset y Gustavo Diéguez quienes dirigen colaborativamente esta investigación de Tesis de maestría.

\section{Caso 1: Territorio Tolosa}

Territorio Tolosa es un proyecto colectivo de contemplación urbana y transformación barrial. Conformado por arquitectas, artistas, vecinos de Tolosa que coordinamos Luciana Lima y Verónica Pastuszuk (arquitectas) desde el 2016. Proponemos observar la ciudad desde una mirada extrañada sobre lo cotidiano; una experiencia sensible de los espacios desde diversas prácticas como: recorridos urbanos, mapeos, performances en el espacio público para promover encuentros vinculares y conocer el barrio (Figura 2).

Realizamos más de 95 recorridos por Tolosa y otras ciudades; participaron fotógrafas, escritoras, dibujantes, artistas, bailarines, actores, maestras, cantantes y vecinos en general. Construimos en cinco años un conocimiento situado del barrio. Y desde allí se comenzó a sistematizar las prácticas territoriales en tres etapas de trabajo: una primera etapa de registro y contemplación urbana, una segunda etapa de sis- 


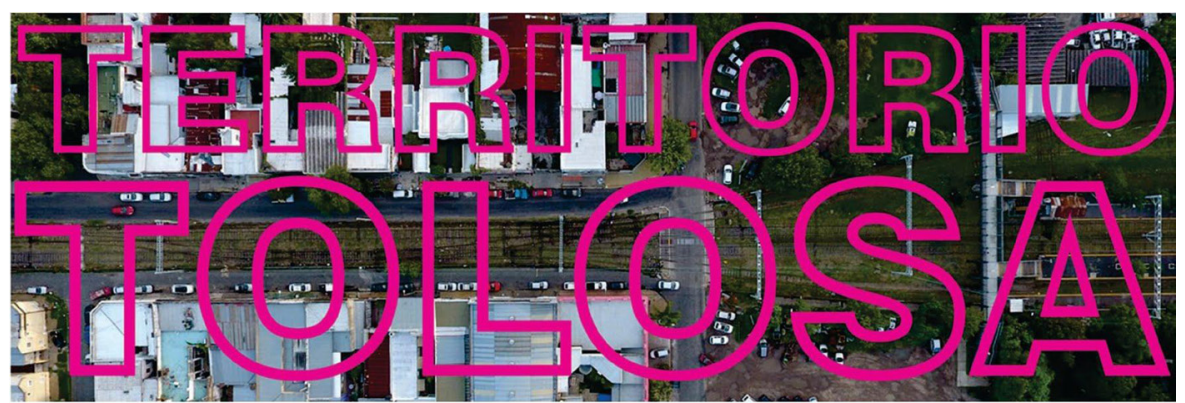

Figura 2: Recorridos y mapeos de Territorio Tolosa. Fuente: Elaboración propia.
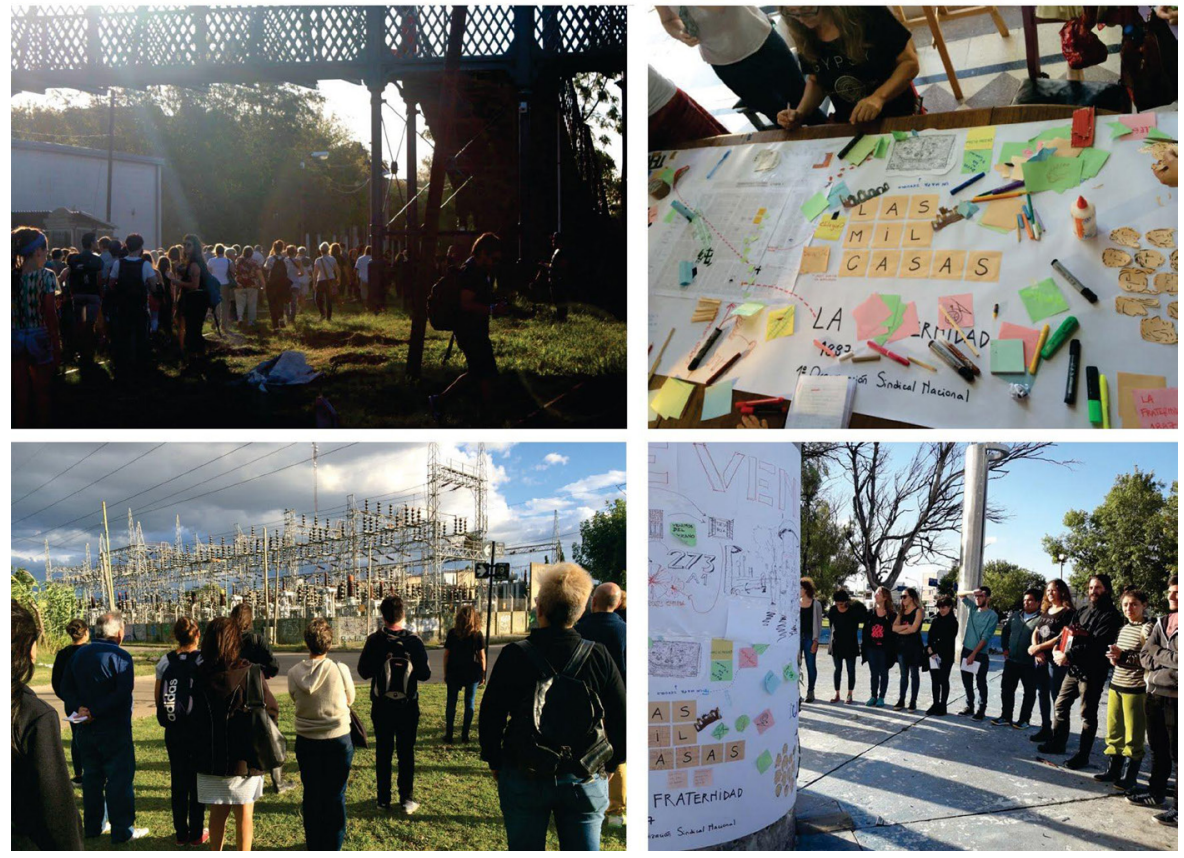

tematización y construcción del marco teórico a partir de generar un conversatorio transdisiciplinar para pensar el barrio de Tolosa y una tercera etapa en la que se encuentra el proyecto de transformación barrial. Esta consiste en la construcción de un proyecto colectivo para el barrio de Tolosa, que surge de todos estos años de investigación y desarrollaremos en este artículo.

\section{Caso 2: La Ciudad Que Resiste}

Otro caso importante para esta investigación es la experiencia de la colectiva La Ciudad Que Resiste, hacia un urbanismo feminista. Es un proyecto de extensión universitaria de la Facultad de Arquitectura y Urbanismo de La Plata, Buenos Aires, Argentina; conformada por arquitectas desde 2018, del que también somos parte. Se desarrolla desde prácticas territoriales participativas, que incluyen recorridos urbanos, talleres y mapeos, para observar cómo el diseño de las ciudades, promovidas por políticas neoliberales, patriarcales, coloniales, han sido diseñadas para un hombre universal como parámetro; dando como resultado ciudades que promueven la desigualdad y la violencia. Este proyecto plantea observar lo urbano desde una perspectiva de género, para intentar deconstruir colectivamente y desde miradas situadas las injusticias sociales. Como también poder hacer visible las resistencias urbanas, aquellas que potencian la empatía, el trabajo colaborativo y comunitario, las organizaciones barriales, autogestivas y tantas otras, que cuestionan los lugares de privilegio hegemónicamente establecidos (Figura 3). 

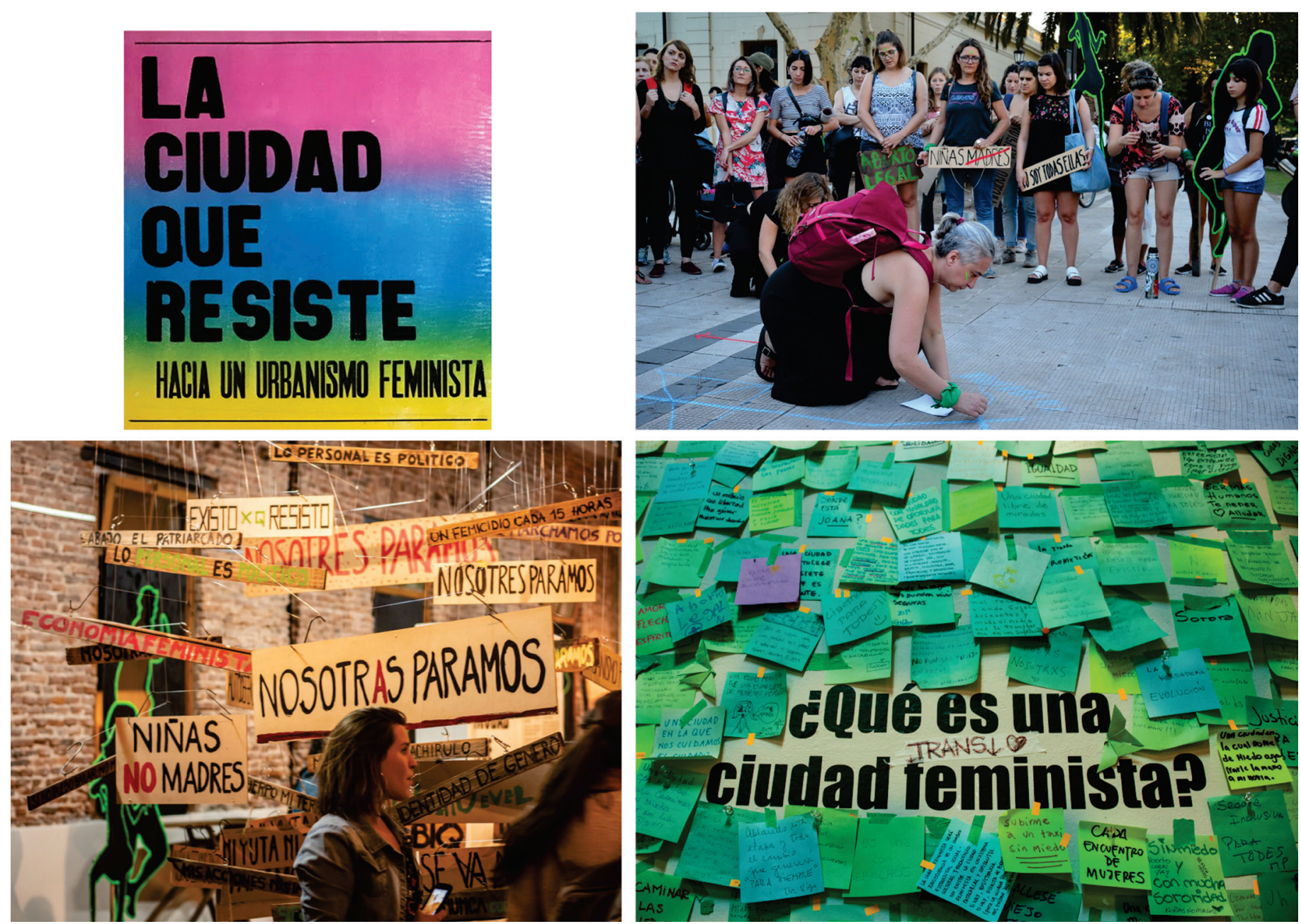

Figura 3: La ciudad que Resiste: hacia un urbanismo feminista. Fuente: Elaboración propia.
Desde estos conocimientos situados podrán abordarse los conceptos de demora, proximidad y cuidados.

\section{Caso 3: Nuestras Arquitectas: Inés Moisset y Carolina} Quiroga, 2019

La propuesta de "Nuestras arquitectas, re-mapeo y nuevas cartografías" propone visibilizar proyectos de mujeres arquitectas que no fueron parte del canon de la época, quedando ocultas en la historia. Plantean prácticas con mapeos y recorridos, como herramientas para: re-enfocar, re-mapear, re-documentar, re-significar, las obras de arquitectura, para obtener nueva información sobre la existente (Figura 4).

\section{(1)

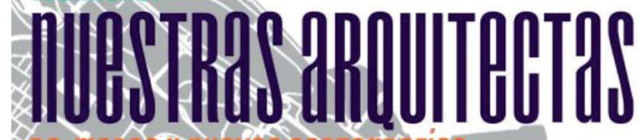
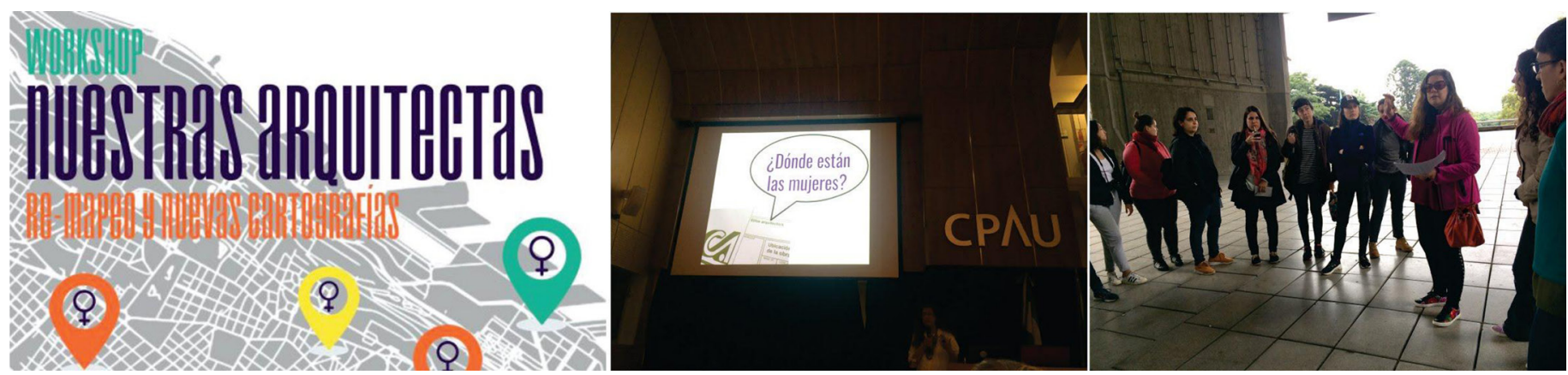

Figura 4: Nuestras Arquitectas. Fuente:

Inés Moisset y Carolina Quiroga, 2019. 


\section{Caso 4: Club Eugenio Necochea en San Martín, a77: Gustavo Diéguez y Lucas Gilardi, 2011}

Por último, un caso de construcción colectiva y comunitaria, es el proyecto para el Club Eugenio Necochea, coordinado por el equipo de arquitectos a77. Plantean el desarrollo de un espacio de encuentro en un barrio en situación de emergencia. Su metodología integral se desarrolla a través de talleres abiertos para estudiantes de arquitectura y de disciplinas afines, para poder conformar un equipo de construcción conjunta con los mismos destinatarios del proyecto (Figura 5).

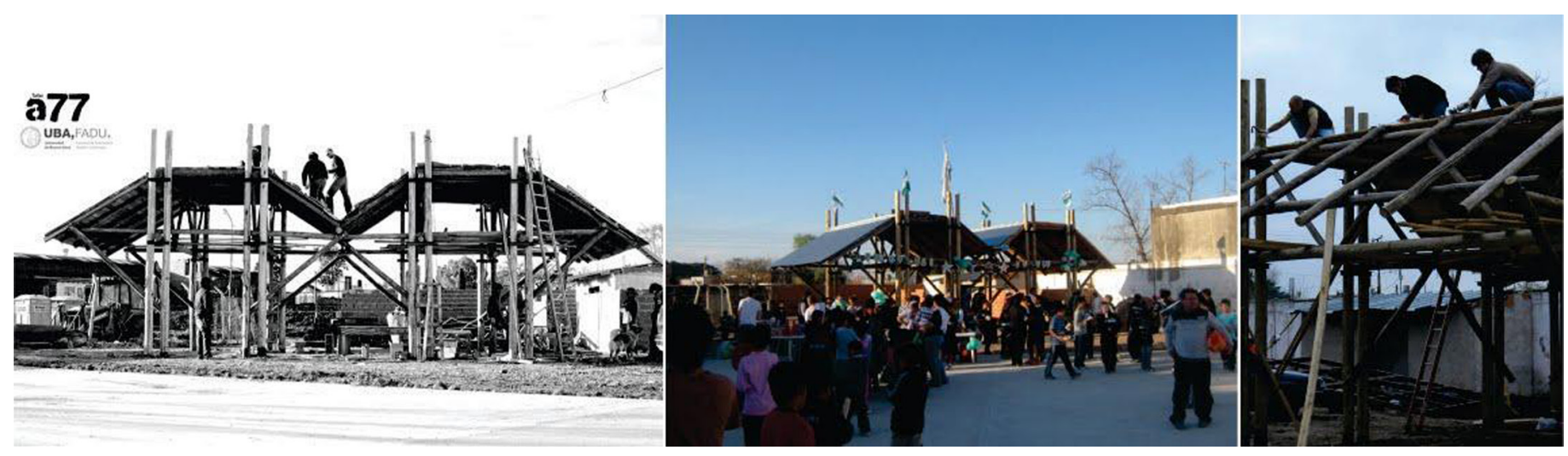

\section{Metodología}

Esta investigación abordará las herramientas del proceso proyectual a partir de dos pautas para el desarrollo del tema: el sitio y las prácticas.

\section{El sitio}

El sitio, de total importancia para la investigación, será en Tolosa, el barrio más antiguo de la ciudad de La Plata, Buenos Aires, Argentina; fundada en 1871. Para abordar el proyecto haremos foco en el predio de los galpones ferroviarios y el barrio de Las mil casas. El predio ferroviario está constituido por una serie de galpones de ladrillo destinados originalmente a locomotoras, construidos entre 1885 y 1887 por el Ingeniero Otto Krause; ocupan un enorme terreno comprendido entre las calles 520, 528, 115 y 3, que incluye la estación de trenes de Tolosa. Este trabajo quiere centrarse en aquellas áreas liminales entre los viejos galpones del siglo xIx, que conectan con el barrio Las Mil Casas. El predio está deteriorado luego de años de abandono y resistencia de una época pasada, donde la naturaleza indisciplinada ha avanzado libremente sobre las fachadas por lo que se destaca como espacio intersticial (Figura 6).

Funciona actualmente un museo ferroviario, una cooperativa textil recuperada, un bachillerato popular, una huerta comunitaria, un club de fútbol, oficinas estatales, la delegación municipal, etc. Por otro lado, Las Mil casas ubicadas en frente, es un barrio particular por su geografía de callejones y parcelas angostas y fue el primer barrio obrero de Latinoamérica creado por Emma de la Barra a fines del siglo xIx; pionera para su época por sus ideas urbanísticas y utópicas (Figura 7).
Figura 5: Club Eugenio Necochea en San Martín. Fuente: a77 (2011). 

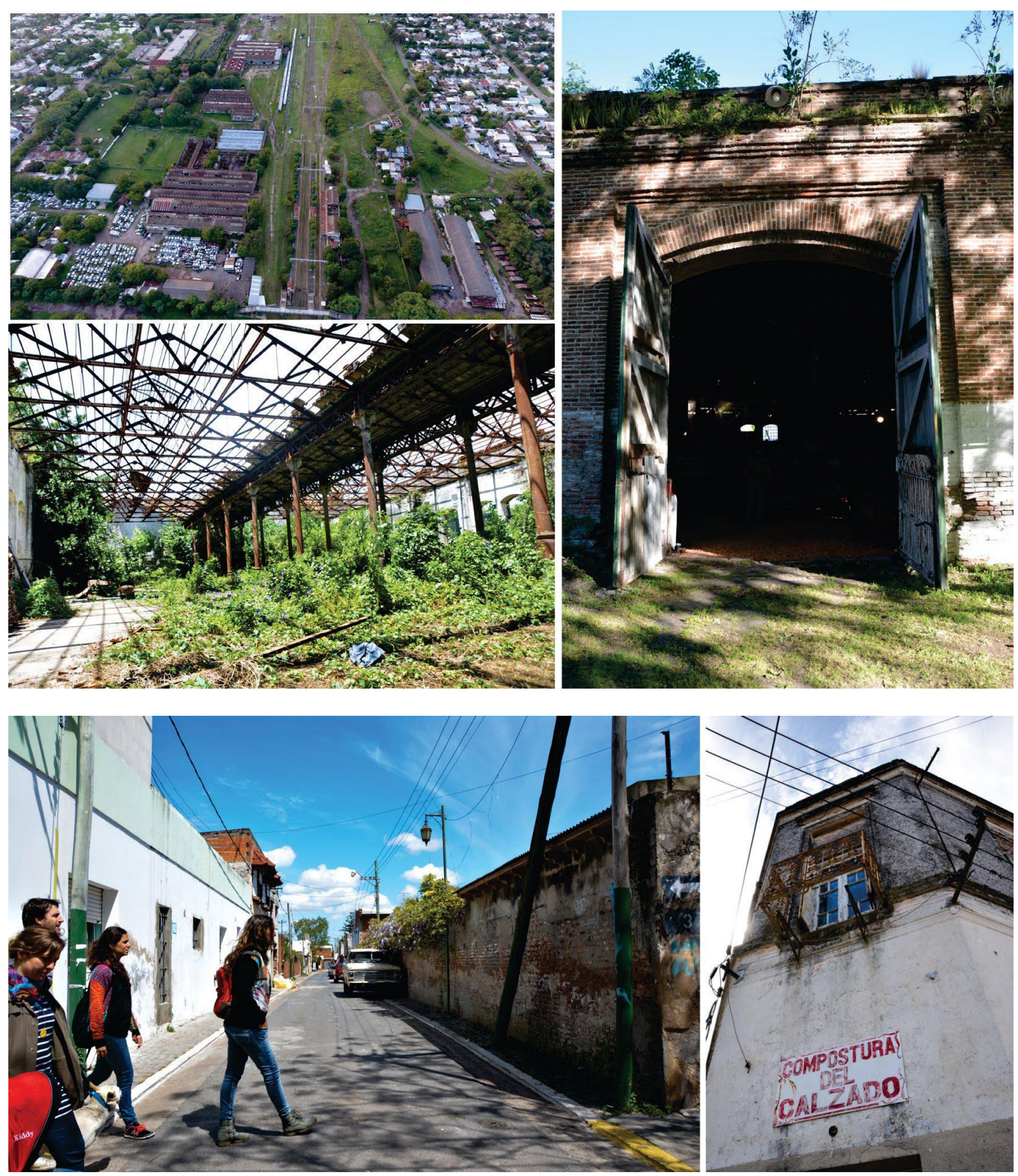

Figura 6 [arriba]: Galpones ferroviarios. Fuente: Elaboración propia.

Figura 7 [abajo]: Barrio Las Mil Casas Fuente: Elaboración propia.
Las prácticas colectivas

Las prácticas son el apartado fundamental de la investigación, es en donde se inicia el proceso proyectual y desde donde se genera la información para desarrollar el proyecto.

Se considera la construcción del proyecto no como algo a priori, sino como un proceso que conecta toda la información obtenida en las prácticas, para construir un proyecto de manera integral que incorpo- 
re múltiples puntos de vista y saberes sobre lo urbano. Es importante para esta investigación el conocimiento singular, situado y sensible del sitio, construido junto a la comunidad. Este proceso será coordinado por los colectivos Territorio Tolosa y La Ciudad que Resiste del que formamos parte junto a arquitectas, artistas y vecinos.

Las prácticas colectivas que detallaremos son: los recorridos urbanos, los mapeos colectivos, los conversatorios transdisciplinares, el laboratorio de proyecto y las asambleas con los y las destinatarias.

Los recorridos urbanos por el predio proponen la experiencia sensorial del territorio; un modo de observación y percepción que requiere pasar tiempo en el lugar, registrarlo, conocer a las personas que habitan el sitio, sus actividades y sus necesidades. La diversidad de registros, obtenidas por diferentes personas, amplía el conocimiento del lugar. Las fotografías, relatos, dibujos, videos, mapas, producen un conocimiento singular y permiten tener un primer diagnóstico de la situación. El sitio elegido es el barrio donde vivimos; esto es muy importante porque somos a la vez proyectistas y destinatarias.

Otra parte del proceso proyectual son los conversatorios transdisciplinares. Estos son una herramienta importante del proceso, ya que permiten construir o ampliar el marco teórico y el estado de la cuestión. Se propone convocar a diferentes referentes locales e internacionales para abordar los temas de la investigación: caminatas urbanas, la ciudad de los cuidados, filosofía, patrimonio y género, las performances en la ciudad, el cuerpo en el espacio público, urbanismo feminista, transformaciones barriales, activismo urbano, gestión y mapeos colectivos. Las miradas transdisciplinares permiten construir una información específica y diversa del tema; se convocará a arquitectos, filósofas, investigadores, artistas, colectivos de activismo urbano, etc. Cada referente invitado hará una propuesta, un diagnóstico del sitio. Desde esa información se obtendrán el programa de necesidades y las primeras ideas proyectuales.

En simultáneo a las prácticas antes mencionadas se realizarán los mapeos colectivos. Estas herramientas permiten reunir los datos y visibilizarlos desde distintos puntos de vista. Deconstruye a su vez los relatos hegemónicos y preconceptos; permitiendo poner en común: ideas proyectuales, casos de estudio referente, programa, etc. El mapa es abierto, conectable en todas sus dimensiones, desmontable, alterable, susceptible de recibir constantes modificaciones (Deleuze y Guattari, 2002).

A partir de conocer el sitio en los recorridos y a las personas que allí habitan, se propondrá en esta etapa conectar con las personas, reunirlas, para empezar a construir colectivamente el proyecto. A esta parte del proceso la llamaremos asambleas con los y las destinatarias. Es aquí donde se producirá, a partir del intercambio de ideas y saberes, un proyecto urbano. En esta etapa proponemos entramarnos nuevamente con el territorio. Se considera que el proceso proyectual no es lineal, sino que es necesario pensarlo en red; porque avanza en múltiples direcciones, y no se construye de manera individual en un estudio de arquitectura u oficina de planeamiento municipal, sino que es una construcción colectiva y situada.

En simultáneo con las asambleas se desarrollará un laboratorio de proyecto barrial colectivo, que irá reuniendo y sistematizando la información del proceso para producir arquitectura, en un proceso dialéctico entre los destinatarios y proyectistas. Consideramos cada etapa del proceso como instancias de participación, cooperación y colaboración. 
Para ello, se conformará un equipo integrado por las colectivas Territorio Tolosa y La Ciudad que Resiste que producirán el anteproyecto.

Este proceso producirá finalmente una metodología que se basa en crear un "destinatario" y "un equipo de proyecto", que antes no existían, y así poder generar un modo de proyectar la ciudad que incluye a la comunidad en un proceso colectivo colaborativo, transdisciplinar y situado.

\section{Propuesta y desarrollo}

En este apartado se relata el desarrollo de las herramientas proyectuales mencionadas anteriormente en la metodología para abordar el proyecto. En este caso se presenta el desarrollo de un anteproyecto debido a los límites de este artículo y el proceso en el que nos encontramos.

\section{El sitio}

Se analizó el sitio a partir de la información reunida, se localizaron los usos, las condiciones de borde, el valor patrimonial del predio, la relación con el tren que atraviesa el barrio. Se decidió seleccionar un área de proyecto de aproximadamente 6 ha., donde se encuentran ubicados los galpones ferroviarios más antiguos, el área patrimonial del predio, entendiendo que este recorte será el motor de una transformación de toda la zona. Allí se localizan: un museo ferroviario, una cooperativa textil, un centro cultural y social, un bachillerato popular, un club de fútbol y un galpón de automotores de la policía. Como también coexisten en el área, la estación de trenes, un puente de hierro, la sala sanitaria, un centro comunal, aunque no todos

Figura 8: Área de proyecto. Fuente: Elina Taccari, 2019. participarán de la misma manera en la generación del proyecto (Figura 8).

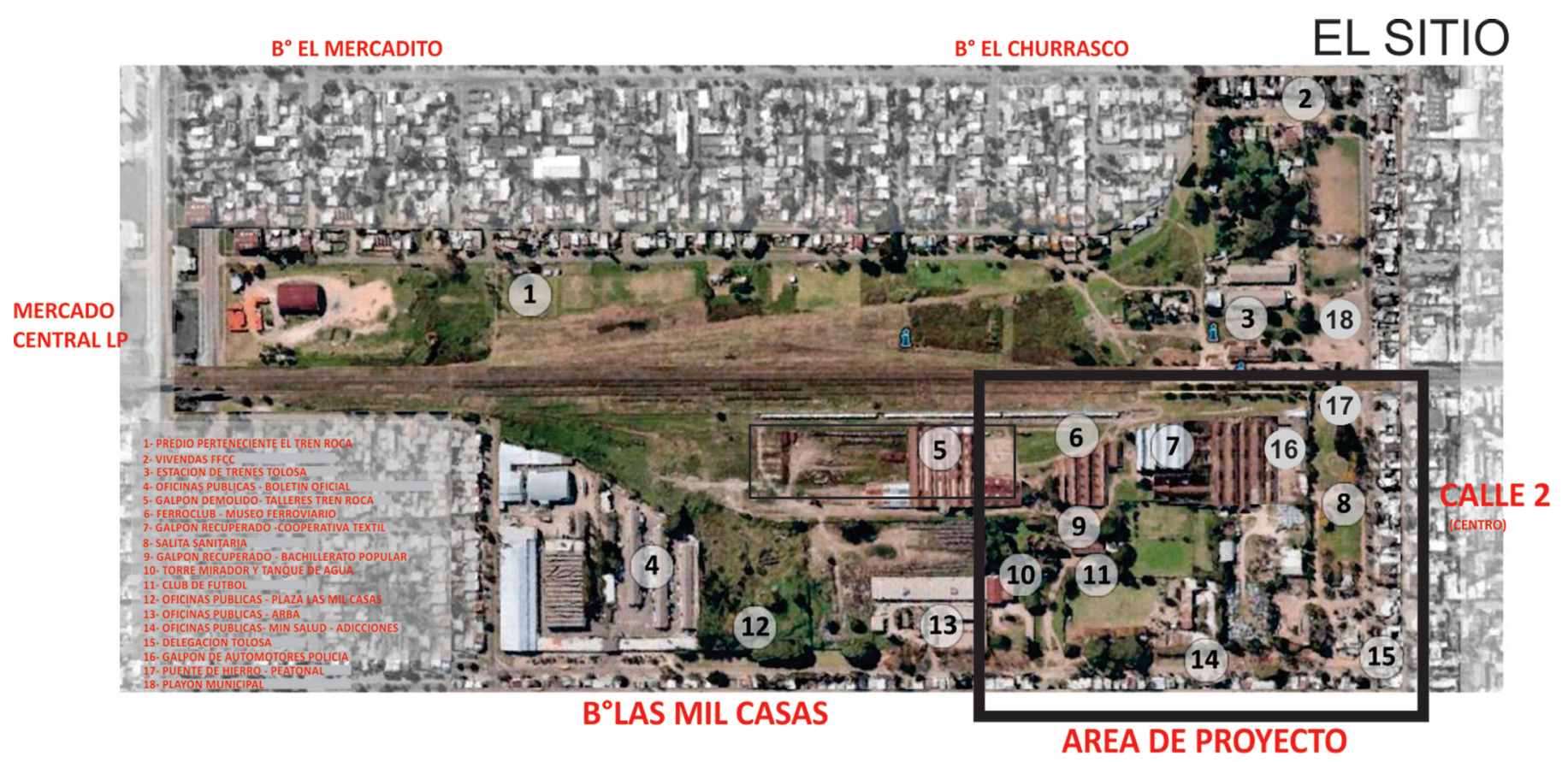




\section{Las prácticas colectivas}

\section{Recorridos Urbanos}

Se realizaron recorridos y registros del sitio por los integrantes del colectivo Territorio Tolosa durante cuatro años. En este tiempo se efectuaron además de los múltiples recorridos, diversas prácticas como concursos de fotos y dibujos para artistas y vecinos del barrio, talleres con caminatas por el sitio, residencias para artistas del barrio, jornadas de plantación de árboles, etc. Esto generó una diversidad de registros del lugar como: fotos, videos, croquis, anotaciones sensoriales, documentos, historias biográficas recolectadas; arrojando un análisis sensible, situado y diverso del sitio. Dicha información reconoce puntos espaciales específicos dónde detenerse a contemplar, como también aquello que habría que preservar y restaurar. Se obtuvieron además registros sonoros de la naturaleza indisciplinada avanzando sobre las fachadas. Se recopiló información sobre los materiales existentes de valor patrimonial que podrían reutilizarse, como ladrillos, tejas antiguas traídas de Marsella, cabriadas herrumbradas, durmientes, estructuras ferroviarias en desuso. También se obtuvo información sobre las actividades y usos del lugar.

Todo ese trabajo colectivo permitió, en el tiempo, obtener un banco de datos situados específicos y diversos como insumo de proyecto, basado en un conocimiento sensible del lugar (Figura 9).

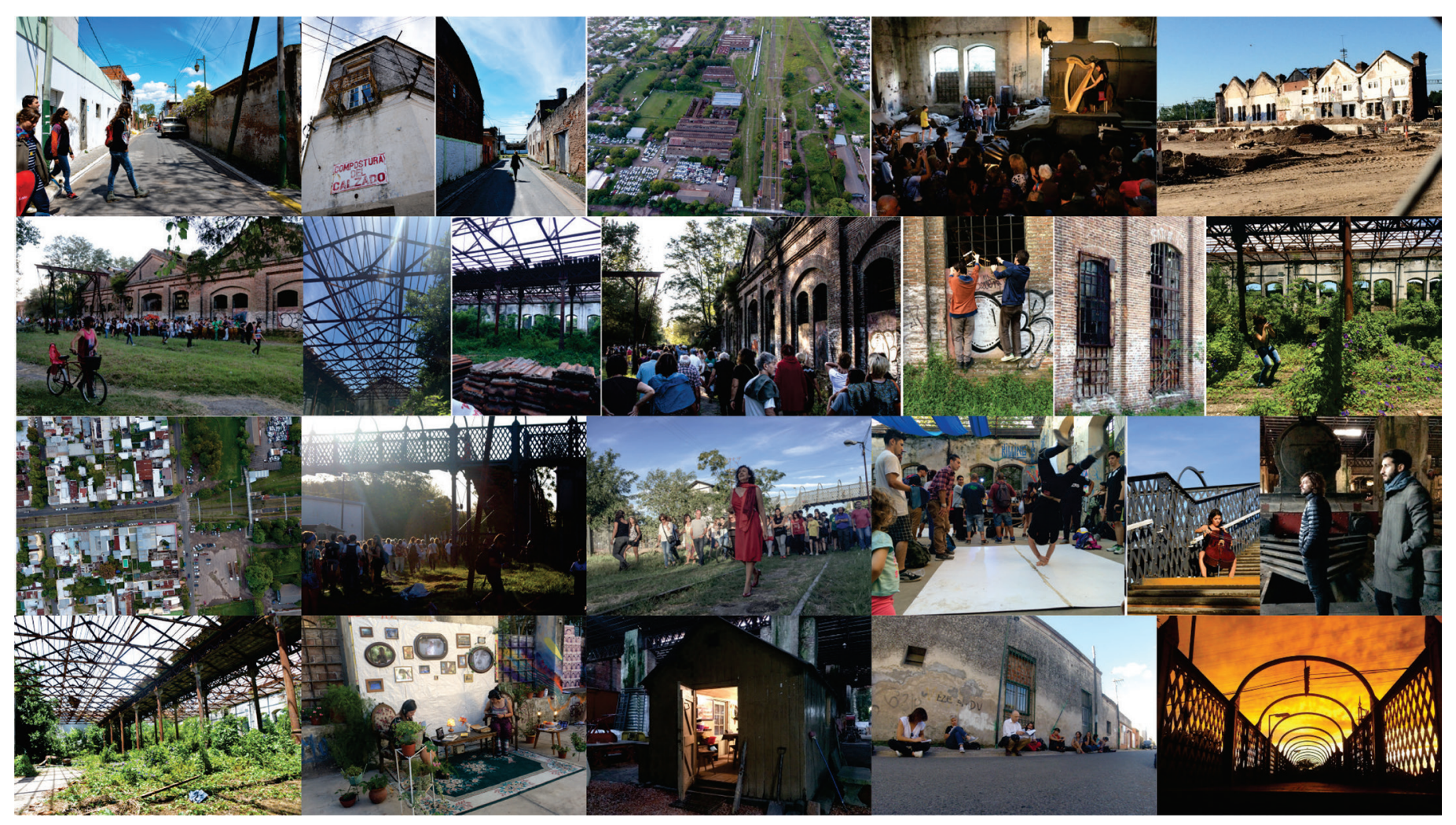

Conversatorios transdisciplinares

A partir de estudiar el sitio e investigar sobre proyectos participativos, como también localizar a quienes trabajan con los temas de demora, proximidad y cuidados, se realizó una curaduría de invitados específicos para debatir, sobre lo urbano y sobre el barrio de Tolosa.
Figura 9: Algunos registros obtenidos en los recorridos por el predio. Fuente: Elaboración propia. 

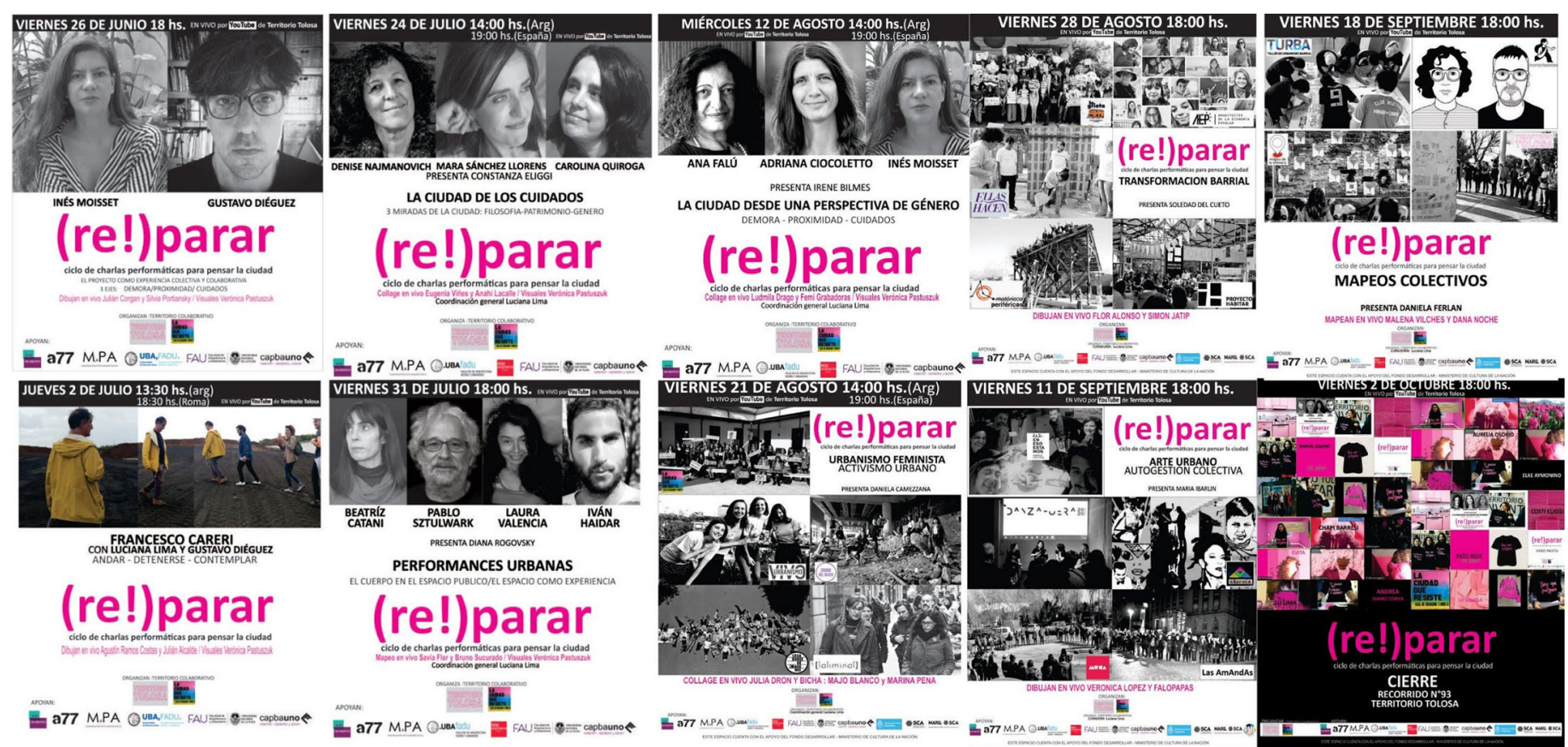

(re!)parar
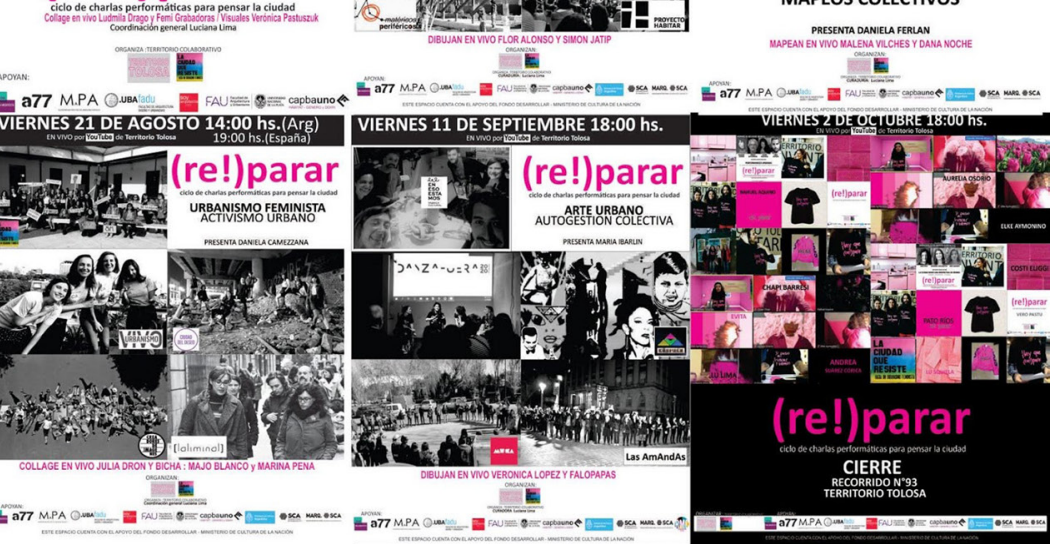

E.

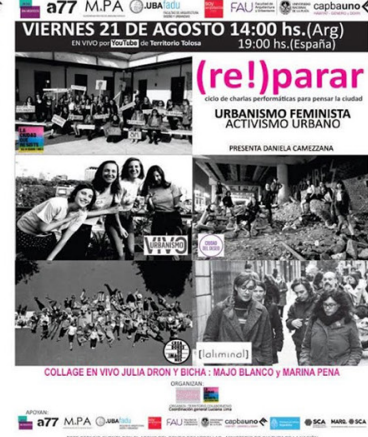

Figura 10: Flyers de los conversatorios transdisciplinares y sus participantes. Fuente: Elaboración propia.

7 Participaron: Inés Moisset, Gustavo Diéguez, Francesco Careri, Denise Najmanovich, Mara Sánchez Llorens, Carolina Quiroga, Constanza Eliggi, Laura Valencia, Beatriz Catani, Iván Haidar, Pablo Sztulwark, Diana Rogovsky, Ana Falú, Adriana Ciocoletto, Punt 6, Irene Bilmes; Ciudad del Deseo, La Ciudad que Resiste, Urbanismo Vivo, Creadores de imágenes, La Liminal, Daniela Camezzana, Arquitectes de la economía popular, La Grieta, Matéricos Periféricos, Proyecto habitar, Ellas Hacen, Soledad del Cueto Danzafuera, En eso Estamos, Cósmiko, Muca, Las Amandas, María Ibarlin, Daniela Ferlan, Evita Ignomirielo, Lucía Squillaciotti, Luciana Lima, Macarena Darino, Elisa Deschamps, Iconoclasistas, Mapas de lo Efímero, Turba, Territorio Tolosa. Además de diferentes performers, artistas y dibujantes que invitamos para generar croquis, videos, e ideas proyectuales. Participaron: Verónica Pastuszuk, Silvia Portiansky, Julián Corgan, Julián Alcalde, Agustín Ramos Costas, Eugenia Viñes, Anahí Lacalle, Savia Flor, Bruno Sucurado, Ludmila Drago, Femigrabadoras, Julia Dron, BICHA, Flor Alonso, Simón Jatip, Verónica López, Falopapas, Malena Vilches, Dana Noche, Elke Aymonino, Chapi Barresi, Nahuel Aquino, Andrea Suarez Córica, Constanza Eliggi, Aurelia Osorio y Patricia Ríos.

8 El ciclo de charlas se llamó (re!) parar y puede verse en este link : https:// www.youtube.com/channel/UCdKil-IcLRBSEuIPzhhXrag.
Contamos con la participación de invitados locales e internacionales transdisciplinares: arquitectas, especialistas en patrimonio, filósofos, artistas, cooperativas de trabajo barrial, activistas y vecinos de Tolosa ${ }^{7}$ (Figura 10).

Las charlas fueron públicas y se difundieron por las redes sociales. ${ }^{8}$ De esos encuentros se construyeron el marco teórico, el estado de la cuestión, las ideas proyectuales y el programa de necesidades generales para desarrollar un plan maestro. Tomar distancia del territorio y poner al barrio como caso de estudio produjo una inmensa cantidad nueva de información transdisciplinar. Estos datos fueron sistematizados en croquis, esquemas, mapas, que luego fueron volcados en la siguiente etapa de mapeos colectivos y en el laboratorio de proyecto. Los croquis fueron realizados por artistas en vivo en los conversatorios (Figura 11).

Como síntesis de esta etapa se construyó un texto colectivo que reúne gran parte de los aportes realizados por los referentes invitados. Y se transformó en un recurso proyectual para cada etapa del proceso. A continuación compartimos un extracto del mismo:

Re parar. Re pensarnos. Ir hacia una identidad colectiva. Generar espacios de encuentro, operar sin producir objetos sino redes y relaciones. Ir hacia una ciudad temporal, demorarse, desurbanizar, pensarnos al aire libre. Transformar la calle en un espacio para estar. En la complejidad del lugar radica la potencia del proyecto. Pensar en multiescalas, multitiempos, multiespecies, abandonar lo binario. Resiginificar y visibilizar es cuidar. Dar forma a los espacios en un proceso junto a la comunidad. Dejarse afectar por los lugares, atravesarlos con el cuerpo, tejer redes de afecto y alianzas para habitar un barrio. Pensar los espacios de manera efímera. Recuperar el riesgo de la experiencia, hacer un museo al aire libre. Lo común como superador del binario: público/privado, pensar en espacios comunitarios, preguntarnos quiénes son las personas que viven en Tolosa. Activar la autogestión y generar ahí un zurcido invisible para los sectores excluidos, ir en contra de la estandarización de los espacios, de los cuerpos, de la vida. Resignificar un lugar. Y re-descubrir el territorio, entrar en un lugar por primera vez, la sorpresa de llegar a un sitio inesperado que queda a la vuelta de tu casa. Pensar la ruina como posibilidad. Practicar la demora, 

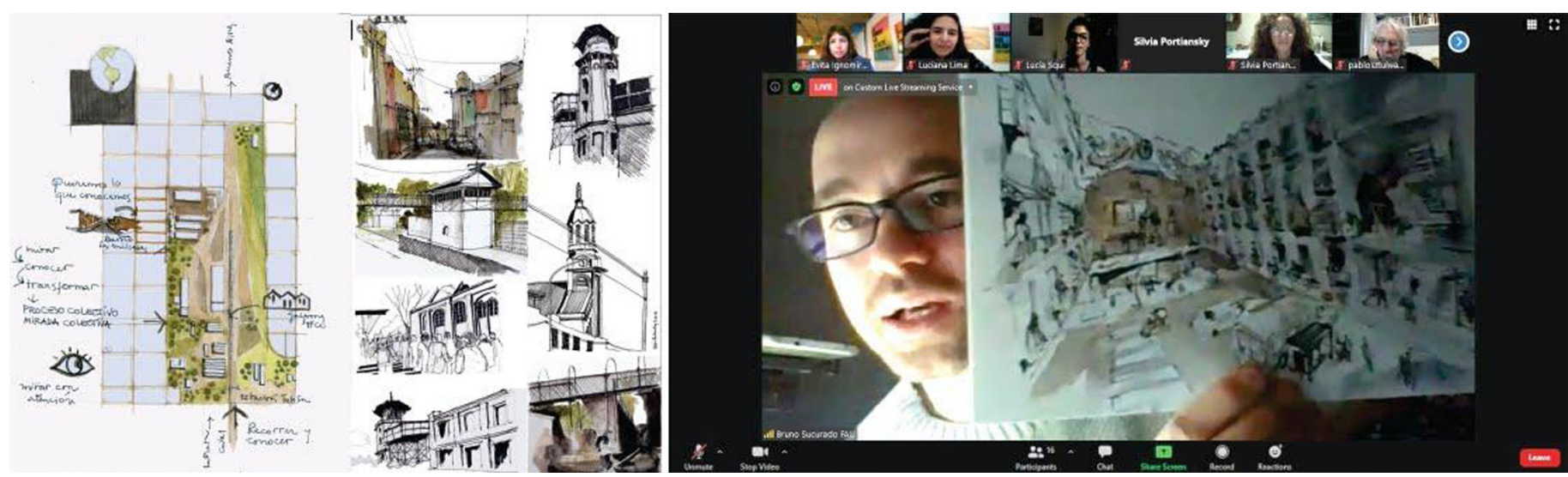

crear nuevas formas de relacionarnos por fuera de las lógicas extractivistas productivas, y fortalecer lazos. Potenciar los saberes ancestrales. Practicar la demora es político. Practicar la demora es poético. Practicar la demora es re parar- nos (re! parar, 2020).

\section{Mapeos colectivos}

Se realizaron diferentes tipos de mapeos colectivos a partir de la información recolectada durante el proceso. La propuesta en esta etapa fue problematizar cartografía y representación. Los mapeos se utilizaron como herramienta para abordar el proyecto arquitectónico. Deleuze y Guatari (2002) conciben al acto de mapear como un acto que apunta a crear nuevos territorios.

Mapeos realizados durante el proceso:

- Mapeo 1: Se superpuso información sobre el proceso histórico y patrimonial del sitio.

- Mapeo 2: Recoge información sobre las características espaciales, luz, sombra, sonidos, naturaleza.

- Mapeo 3: Reúne información sobre los usos, programas y ocupaciones del predio.

- Mapeo 4: Visibiliza los relatos recogidos sobre el sitio, historias, anécdotas, narraciones orales.

- Mapeo 5: Proyecta los múltiples recorridos posibles por el sitio.

- Mapeo 6: Superpone las diversas ideas proyectuales propuestas en el proceso.

A partir de esta nueva información se realizaron operaciones de reinterpretación, re-escritura, vinculación y superposición. Algunas estrategias realizadas sobre los mapas fueron: relacionar, aislar, seleccionar la información. Para ello se generaron croquis y collages, que recodificaron lo observado para ser elaborado luego en la etapa de Laboratorio de proyecto. Estas herramientas proyectuales permiten abordar la forma arquitectónica a partir de una mirada diversa y múltiple sobre el sitio. El mapa es desmontable, conectable, alterable. Las relaciones no se encuentran determinadas, el mapa se construye (Deleuze y Guattari, 2002). La construcción colectiva de los mapeos, que se han nutrido de las experiencias, los relatos recogidos, de pasar tiempo en el barrio, permite la apropiación sensible del territorio, impugnando representaciones hegemónicas de los mismos, para producir nuevas narraciones colectivas, abiertas a pensar otras realidades para dar forma a la arquitectura. Dar forma es dar sentido (Onfray 2000) (Figura 12).
Figura 11: Cartografías urbanas de los conversatorios. Fuente: Silvia Portiansky y Bruno Sucurado, 2020 


\section{Asambleas con los y las destinatarias}

Las asambleas con los y las destinatarias se realizaron en simultáneo con el Laboratorio de proyecto. Esta parte del proceso permitió retomar el contacto con quienes desde hace más de 20 años resisten en el predio. Propusimos las asambleas para reactivar las relaciones entre los colectivos que habitan el lugar. Hoy en día estas relaciones están en tensión o sin vínculo alguno, debido a años de resistencia por falta de visibilidad, apoyo estatal o un marco legal que los ampare. Esta etapa consistió en la construcción del grupo que llamamos: los y las destinatarias. Nos propusimos vincularlos para colaborar en organizarlos y potenciarlos. Es una propuesta de esta investigación, construir dos cuestiones claves: los/las destinatarias y los/las proyectistas, para una construcción colectiva y comunitaria de un proyecto.

A partir de asambleas, encuentros grupales con la mediación del colectivo Territorio Tolosa (equipo de proyecto), se generó la posibilidad de diálogo entre las partes, para crear un proyecto común que integre a los vecinos del barrio y vincule el predio de los galpones ferroviarios con el tejido urbano hoy abnegado (Figura 13). Invitamos también a diferentes referentes en gestión pública para acompañar los avances del anteproyecto hacia la factibilidad de una futura ejecución del proyecto de transformación barrial.

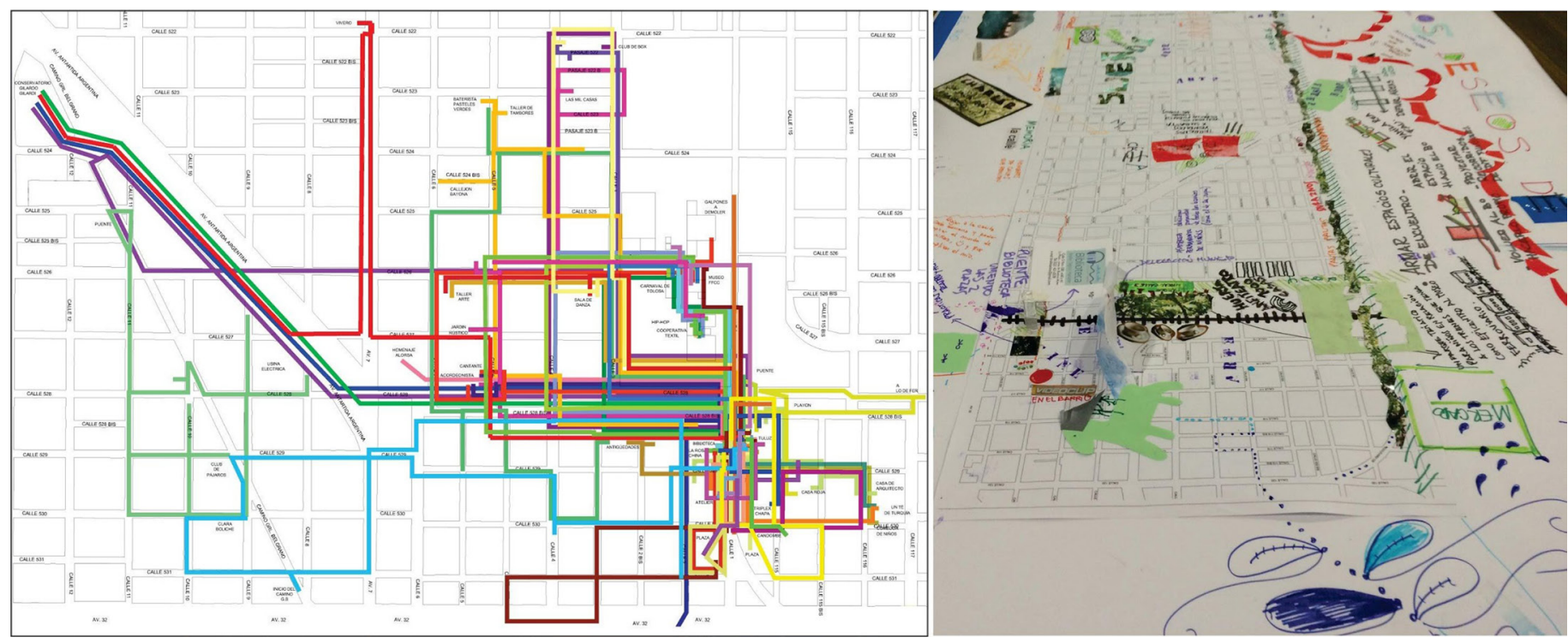

Figura 12: Mapeo de recorridos por Tolosa. Fuente: Elaboración propia. ${ }^{9}$
Uno de los planteos más fuertes de los destinatarios fue la construcción de un parque temático ferroviario, un proyecto que vienen imaginando algunos sectores desde hace 20 años. Tomamos esa idea como punto de partida para revalorizar el patrimonio de Tolosa y su relación histórica con el tren. Una de las actividades que realizamos fue recolectar las propuestas de vecinos, arquitectas, urbanistas, artistas, ferroviarios y gente del predio, para pensar conjuntamente cómo podría ser ese parque ferroviario en Tolosa.

Aquí compartimos un extracto de esas voces del barrio con propuestas para el parque temático:

Un parque ferroviario debería que recuperar la historia de Tolosa y el ferrocarril. Debería ser un parque público atravesable. Que no existan alambrados.Un parque con mucha vegetación, donde puedan crecer libre-
9 Ver otras imágenes de mapeos colectivos realizados en el apartado: Estado de la cuestión, caso 1 , Territorio Tolosa. 


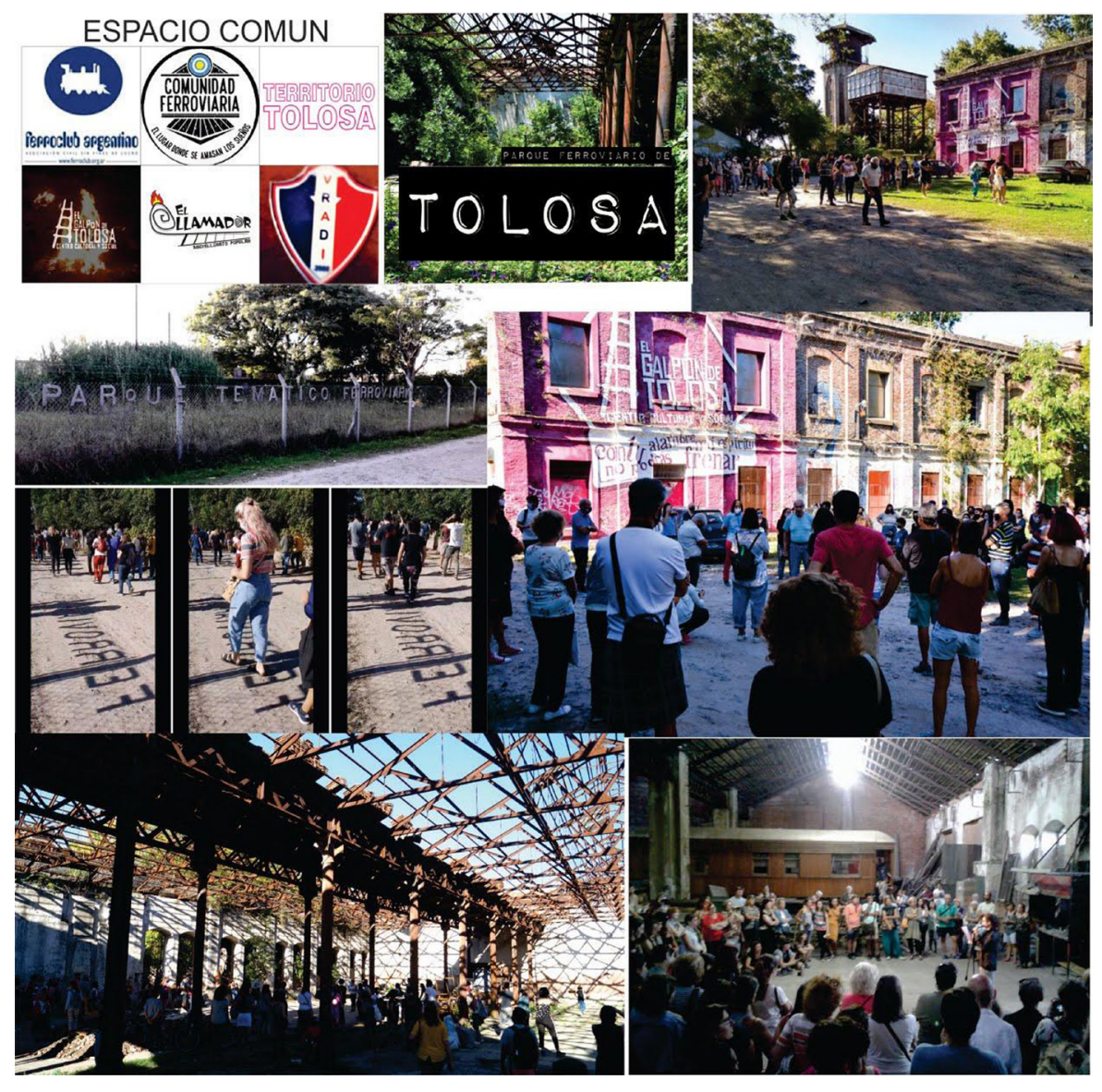

mente las plantas nativas y las plantas típicas del tren. Que se restaure la torre-tanque de agua de los ferrocarriles a vapor y transformarlo en un mirador de Tolosa. Recuperar el viejo tendido de vías para un tren que recorra el predio en un circuito turístico. Un parque recreativo donde los chicos jueguen con sus abuelos y escuchen el sonido del tren. Un espacio que reafirme la cultura ferroviaria, creando un parque temático con esculturas. Resignificar los galpones del siglo xix con funciones culturales, para ferias, recitales, anfiteatros, al aire libre. Un parque de la memoria que recupere la historia del barrio Las mil casas, el 1. ${ }^{\text {er }}$ barrio obrero de Latinoamérica frente a los galpones. Un parque para que la gente del barrio se reúna y conozca su propia historia. ${ }^{10}$

Antes de finalizar esta etapa queremos contarles quienes son los y las destinatarias: El Ferroclub, museo ferroviario que preserva trenes desde 1997; Comunidad Ferroviaria, cooperativa textil y carpintería; El galpón de Tolosa que es un centro cultural, social y bachillerato popular; Vradi un club de fútbol infantil; Automotores de la policía, que ocupa uno de los galpones destinado al depósito de autos en desuso; Territorio Tolosa como el colectivo mediador entre las partes.

\section{Laboratorio de proyecto}

\section{Barrial, colectivo, colaborativo y transdisciplinar}

En esta etapa, se reúne la información previa, proveniente de los recorridos, los conversatorios y los mapeos, para construir el anteproyecto. Un proceso de conversaciones y correcciones con los y las destinatarias, descrito en el apartado anterior. Se organizaron esquicios para sistematizar la información reunida por Territorio Tolosa. A este
Figura 13: Asambleas con los y las destinatarias para generar el anteproyecto. Fuente: Elaboración propia.
10 Parte de estas actividades pueden verse en el video realizado por Territorio Tolosa. Colaboraron: Maia Tinto, Rocío Roo, Nahuel Aquino, Julián Alcalde, Eribó cuerda de candombe, Octopo Tolosa, los colectivos del predio y vecinos del barrio.Puede verse en este link: https://youtu.be/pDLw-qGxaAI. 
proceso lo llamamos constelar la información. Constelar es un proceso que hace síntesis de la información para redirigirla y generar nuevos vínculos. Activar la constelación es ir más allá del mapeo o sistematización; porque se constela información sensible, basada en vínculos, relaciones, cuidado, afecto. La información constelada fue: marco teórico, registros del sitio, ideas proyectuales, casos referentes, mapeos, programas (Figura 14).
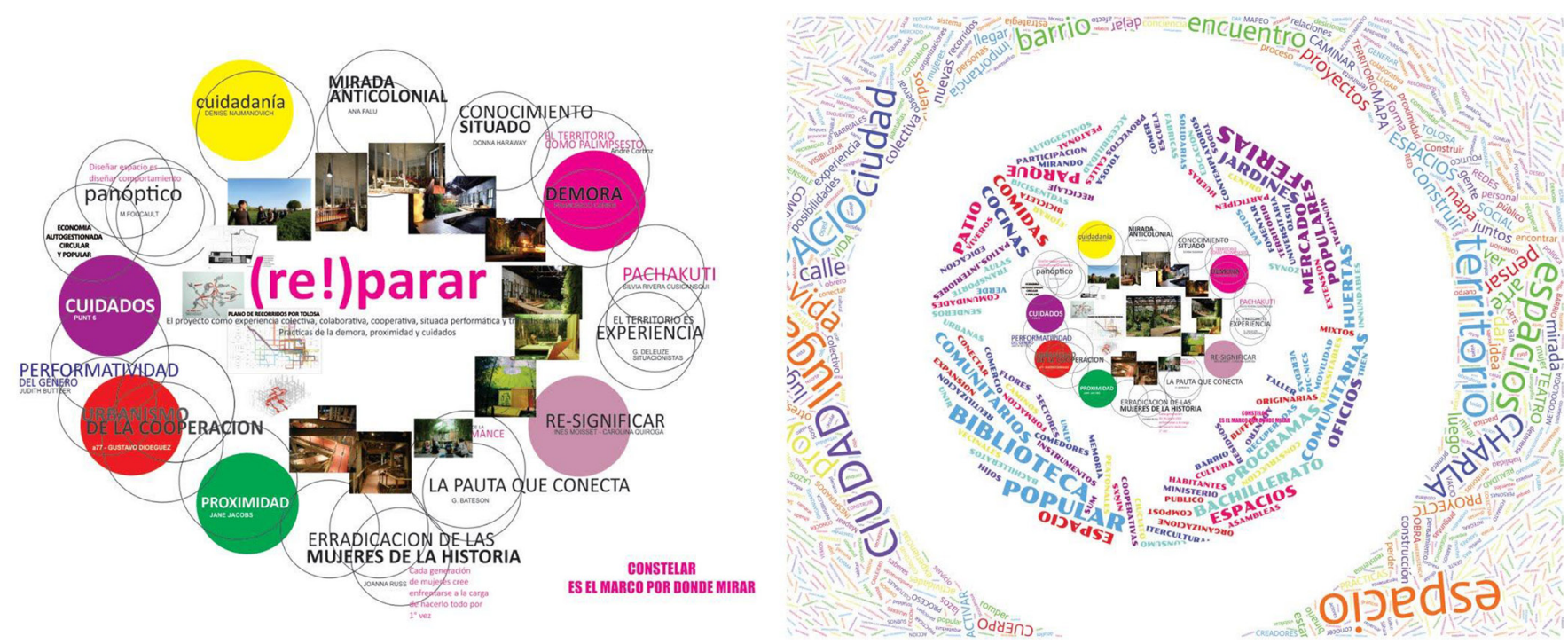

Figura 14: proceso de constelación de la información. Fuente: Elaboración propia.
Se profundizó además en la propuesta de los y las destinatarias de crear un parque ferroviario en Tolosa y se hizo hincapié en 5 líneas de investigación para desarrollar el anteproyecto: demora, proximidad, cuidados, resistencia, colectiva (Figura 15).

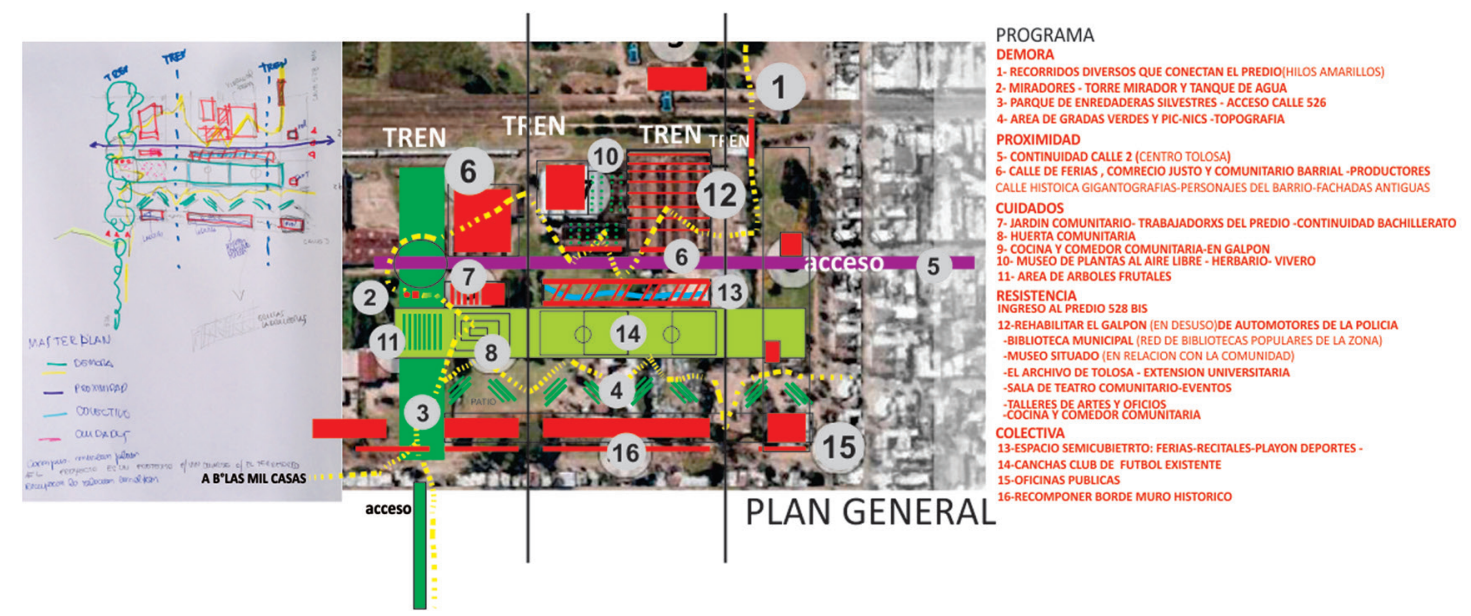

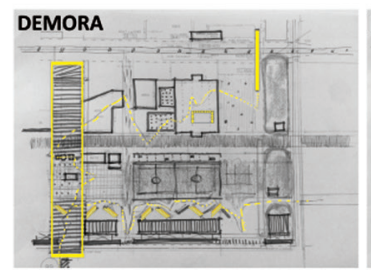

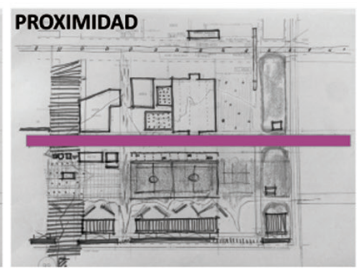

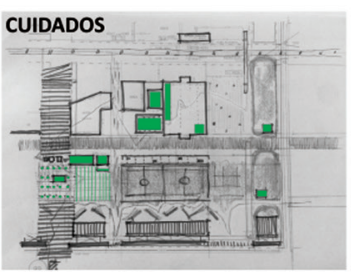
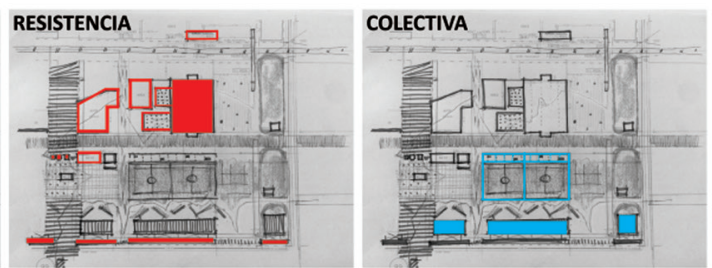

Figura 15: Plan general. Fuente: Elaboración propia.
El anteproyecto se generó a partir de seleccionar diferentes ideas proyectuales propuestas en el proceso. Una de ellas fue la de materializar los recorridos posibles por el predio. Se propuso generar caminos que 
conecten el sitio, proponiendo espacios para la demora, la contemplación y la proximidad, a partir de la información mapeada (Figura 16).

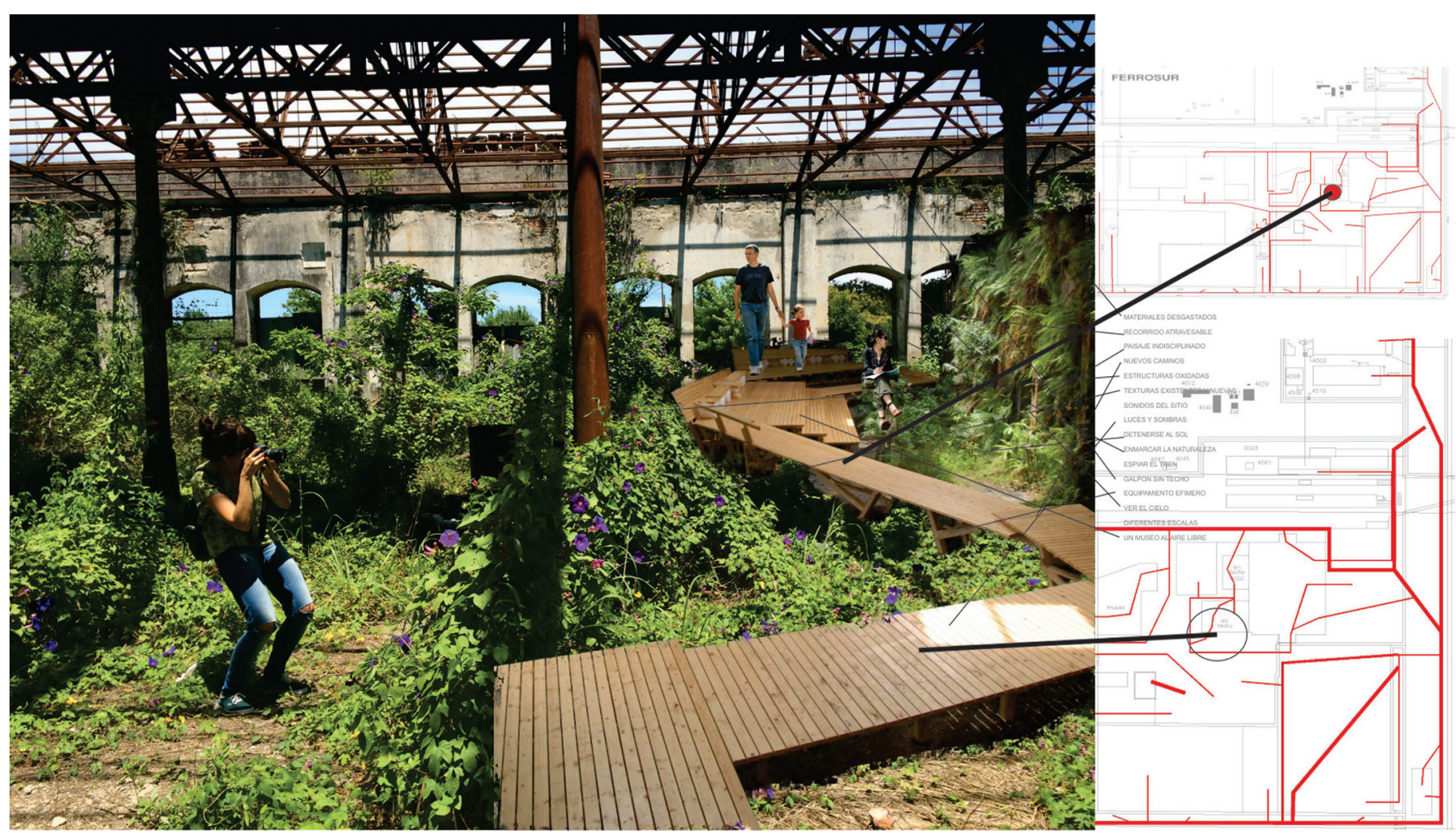

Se propuso una intervención sutil, de bajo impacto, que genere recorridos, desvíos, que permitan la experiencia sensible del territorio. Se diseñaron una serie de pasarelas de madera, que en su despliegue se van transformando en gradas donde detenerse a contemplar, en refugios, en miradores, en anfiteatros. Se propuso una intervención temporal que sea afectada por el paso del tiempo, que no colonice la singularidad del predio, una arquitectura de piso que se despegue apenas del suelo para que el entorno pase por debajo, por arriba, que conecten el predio con los usos existentes y permitan que la gente del barrio pueda atravesar el espacio a fin de experimentar el territorio de un modo no invasivo. Son estructuras de pequeña escala que permiten la autoconstrucción.

El anteproyecto propone una serie de nuevos caminos como el que cruzan el antiguo galpón sin techo; donde conviven la arquitectura y la ruina. Una geometría simple, que surge de los datos obtenidos por las diferentes prácticas: conversatorios, recorridos, mapeos, asambleas. La propuesta plantea generar un mismo tipo artefacto, que se pliega y despliega para crear distintas formas de habitar el espacio: estar, recorrer, contemplar, detenerse, jugar, para potenciar el territorio preexistente. Se propone entonces un parque ferroviario conectado por estos nuevos recorridos entre los galpones y las estructuras existentes.

En la línea proximidad trabajamos la idea de espacio de encuentro comunitario, tomando como referentes el callejón del barrio obrero de Las Mil Casas y el callejón del proyecto SESC Pompeia de Lina Bo Bardi en São Paulo. Se propuso crear una calle peatonal como continuación del la calle comercial de Tolosa. ${ }^{11}$ Se propuso abrir una calle que hoy no existe, que atraviese el predio para generar un recorrido que vincule al barrio con las fachadas antiguas de los galpones; cami-
Figura 16: Collage de anteproyecto, materialización de los caminos. Fuente: Elaboración propia.

11 La calle 2 es la calle comercial del barrio, la zona céntrica de Tolosa que conecta con la plaza principal. 
nar entre las fachadas del siglo xIx, para recuperar la historia, los personajes del barrio con gigantografías. Se propone allí un espacio para ferias, festejos barriales, eventos, que reúna a la comunidad y los productores del barrio de Tolosa (Figura 17).

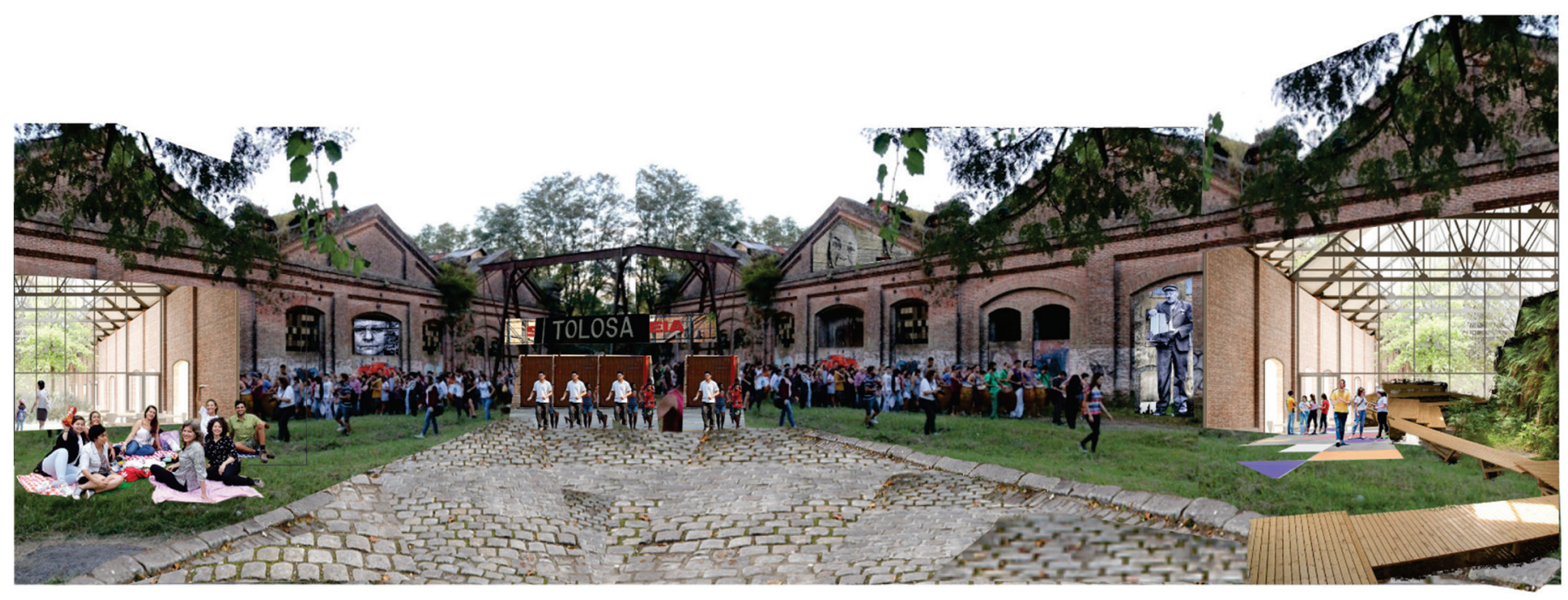

Figura 17: Proximidad. Callejón peatonal. Fuente: Elaboración propia.

Figura 18: Cuidados / Colectivos. Jardín, huertas, torre mirador y tanque. Fuente: Elaboración propia.
En la línea de cuidados nos planteamos dar espacio a las tareas reproductivas, potenciando la propuesta de democratizar los cuidados. Para ello, se propuso realizar a continuación del bachillerato popular existente, un jardín de infantes comunitario y una huerta común para todo el predio, que abastezca a quienes allí trabajan para fomentar las tareas colectivas y de cuidado. Para ello se piensa en continuar con la estructura del galpón existente, replicando su formato; generando un
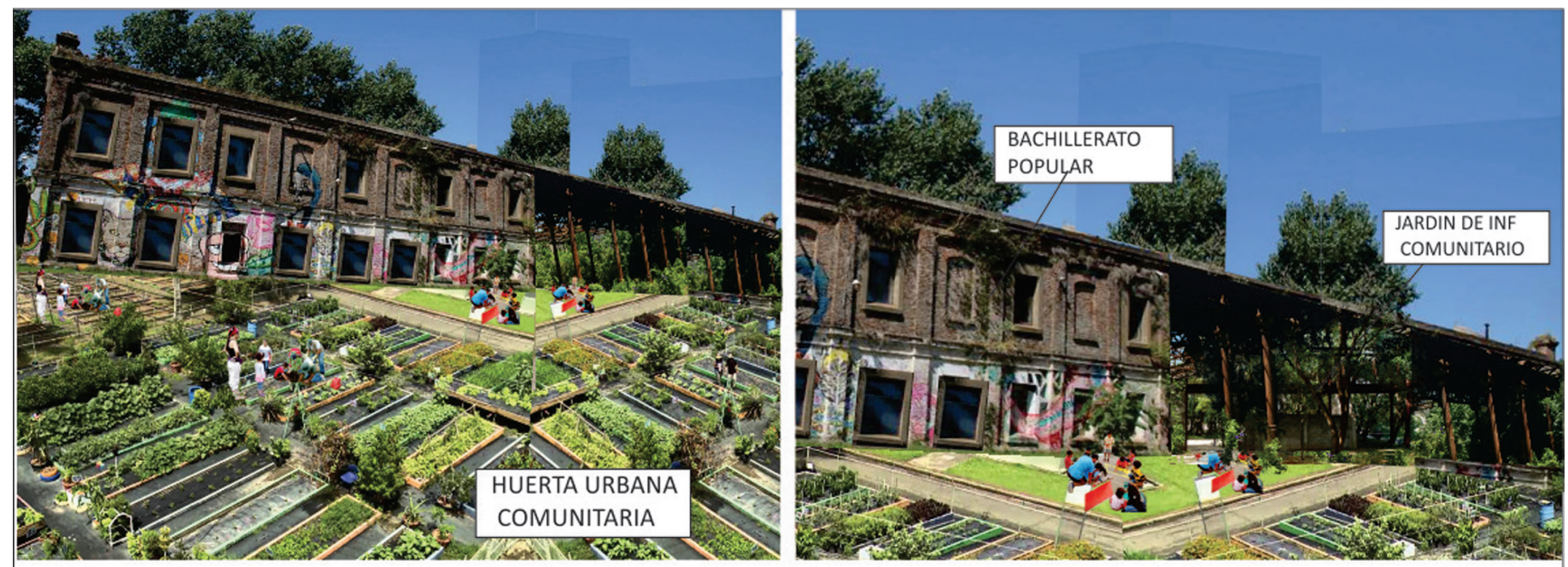

\section{RESIGNIFICAR LAS ESCTRUCTURAS DEL PASADO}

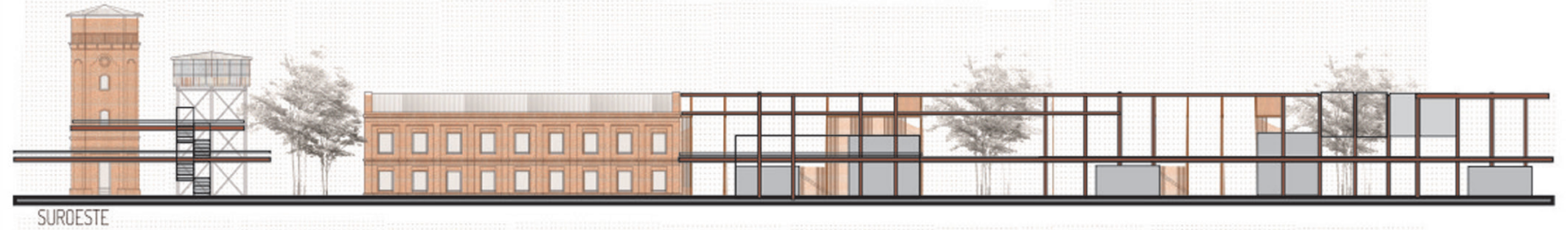


espacio que albergue al jardín de infantes y otros usos de sombra, espacio semicubiertos, playón deportivo-recreativo y juegos, relacionándolos con la huerta comunitaria. También se propuso como otra de las ideas, cuidar el patrimonio, poner en valor los hitos del predio: eso significa restaurar la torre tanque de agua, que abastecía antiguamente a los trenes, y transformarla en un mirador como punto panorámico de Tolosa (Figura 18).

En la línea resistencia se profundizó en cómo resignificar el patrimonio industrial del siglo xıx, reflexionando sobre qué programas deberían alojar hoy los galpones ferroviarios. Se plantea un programa que potencie a los colectivos que existen y resisten en el predio. Considerando fundamental dar visibilidad a aquello que resiste, no solo a las personas que preservan el lugar, sino la resistencia material de los galpones, la resistencia de la naturaleza, la resistencia espacial, el valor arquitectónico, que tiene un espacio de la escala de los galpones para el barrio. Hablamos de la resistencia a ser demolidos (como ocurrió en 2018).

Una resistencia al paso del tiempo. Se propone entonces la rehabilitación de unos de los galpones, el galpón de automotores de la policía, que hoy se encuentra en estado de abandono, utilizado como depósito de autos en desuso y patrulleros herrumbrados (Figura 19).

RESISTENCIA

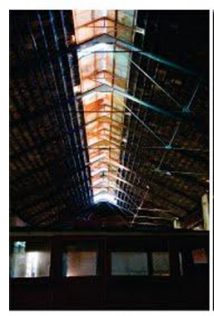

RESISTENCIA MATERIAL
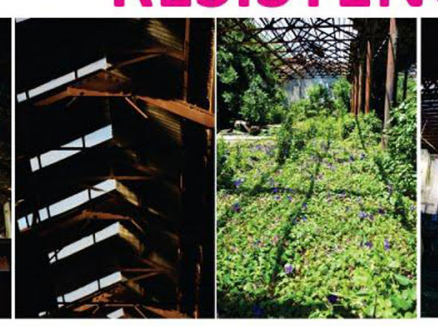

RESISTENCIA DE LA NATURALEZA
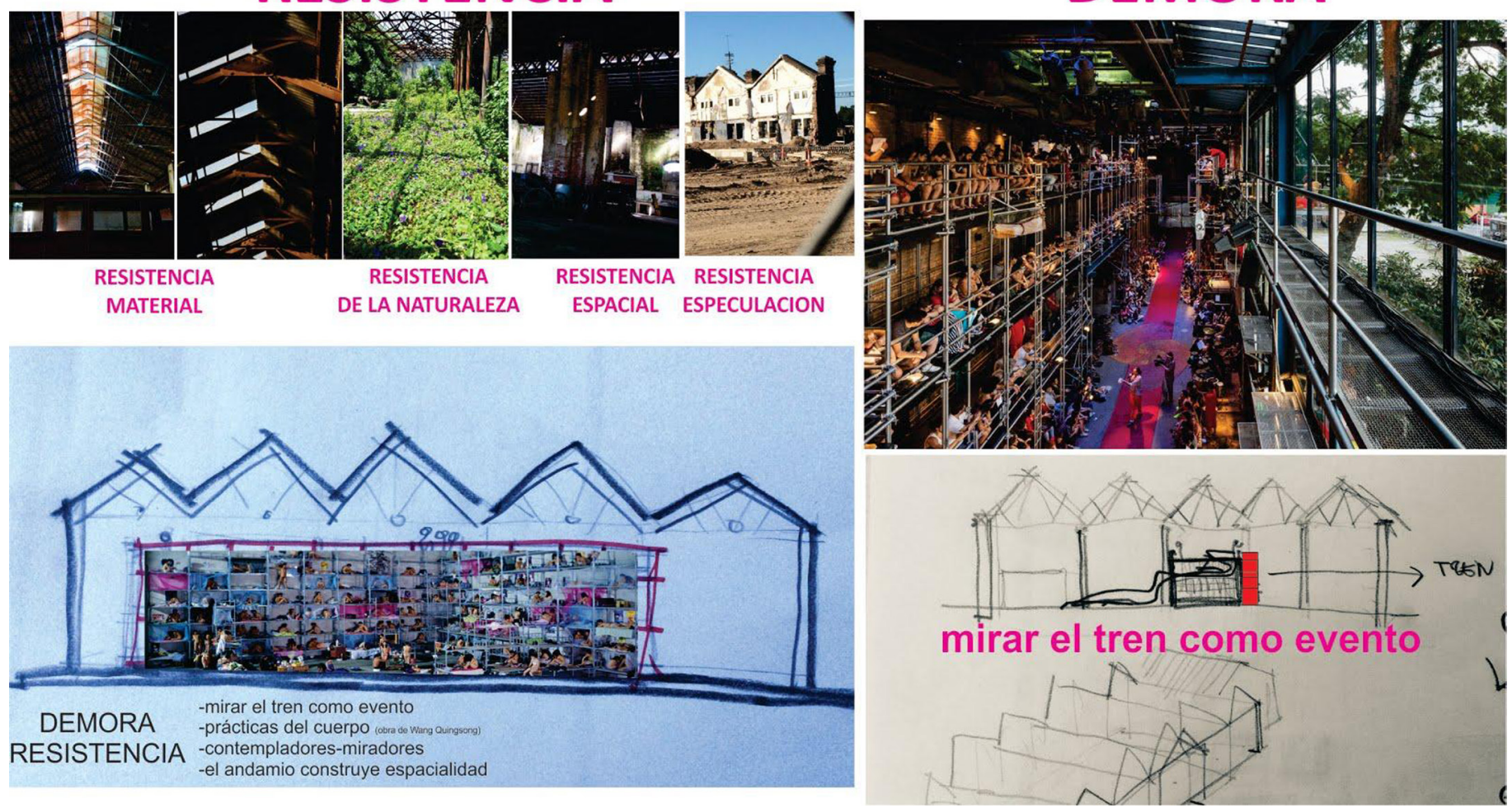

Se plantea este galpón como nuevo punto de accesos al predio, como el nodo de todo el proyecto. Esta gran intervención plantea transformar el área en un polo comunitario, que nuclee las distintas actividades de la zona: productores, bibliotecas populares, clubes, etc. Se propone entonces generar en el galpón de automotores, un centro comunitario que reúna al barrio y lo conecte nuevamente con la ciudad.

Para comenzar, se tomó una idea proyectual propuesta en el proceso: "mirar el tren", una práctica singular que caracteriza al barrio. Su
Figura 19: Resistencia. Fuente: Elaboración propia. 
sonido es parte del paisaje y la identidad de Tolosa. El galpón de automotores limita con la vía, por eso en el laboratorio de proyecto se exploró esa práctica: “contemplar el tren como evento". Se planteó una grada/andamio que, además de percibir el tren, pudiera servir de palco para un teatro comunitario, o espacio para reposar, o lugar de lectura. Proponemos realizar las mínimas intervenciones restaurando el galpón para potenciar el patrimonio sin colonizarlo ni arrasarlo. Tomamos de referente el Teatro Oficina de Lina Bo Bardi y Edson Elito y la obra del artista Wang Qingsong, como punto de partida en el anteproyecto.

Finalmente, estas propuestas son apenas un punto de partida para hacer visible el proceso de trabajo. Como síntesis del anteproyecto para Tolosa, se propone un polo comunitario que incluya: un parque ferroviario atravesado de nuevos y múltiples recorridos para propiciar la demora. Una calle peatonal para promover la proximidad, con espacios de encuentro entre productores locales, artistas y vecinos. Un centro comunitario que ponga en valor el patrimonio material de los galpones y la identidad del barrio. Y un jardín comunitario junto a una huerta común para dar espacio a las tareas de cuidados colaborativos y promover la soberanía alimentaria. Proponemos así un proyecto de transformación barrial creado junto a la comunidad (Figura 20).

\section{SINTESIS}

DEMORA

PROXIMIDAD

RESISTENCIA

CUIDADOS

COLECTIVA

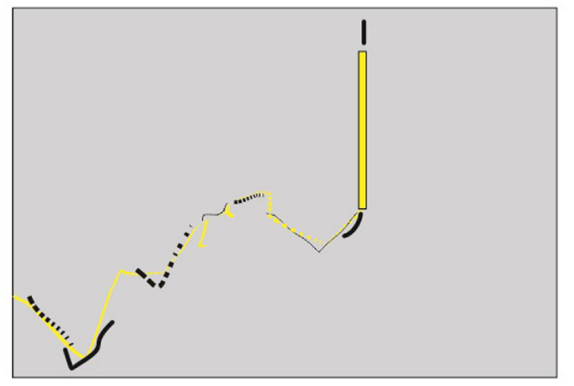

PARQUE FERROVIARIO

RECORRIDOS

CALLE

ANDAMIO

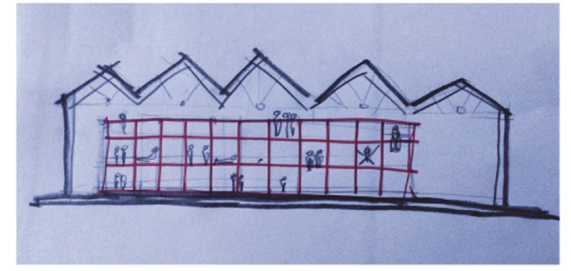

CENTRO COMUNITARIO

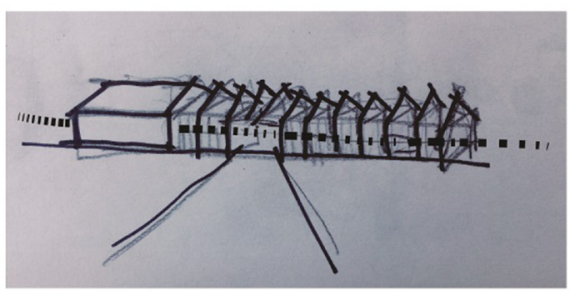

JARDIN COMUNITARIO HUERTA/HERBARIO
Figura 20: Esquemas proyectuales para un polo comunitario en Tolosa. Fuente: Elaboración propia.

\section{Conclusiones}

Esta investigación pone en relación los conocimientos situados recopilados por el colectivo Territorio Tolosa, desde el año 2016, e incorpora toda la información generada por una serie de herramientas proyectuales definidas como prácticas colectivas constituidas por: recorridos urbanos, conversatorios transdisciplinares, mapeos colectivos, laborato- 
rio de proyecto y asambleas con los y las destinatarias. De este proceso surge como resultado una metodología participativa para abordar el proyecto urbano que incluya a la comunidad.

También surgen dos cuestiones claves de mencionar para el desarrollo de un proyecto colectivo; la creación de un equipo de proyecto y otro grupo conformado por los y las destinatarias (que antes no existían).

Desde estas prácticas se propusieron espacios para la demora, proximidad y cuidados para resignificar el patrimonio del predio de los galpones ferroviarios, sin colonizarlos ni arrasarlos. A su vez se observó que poner en práctica un proceso que cuestione el modo unilateral, autosuficiente y apriorístico de producir el proyecto arquitectónico; deconstruye los formatos hegemónicos académicos, profesionales y de gestión urbana. Esta investigación propone, entonces, una metodología de trabajo colectivo, colaborativo y transdisicplinar; que promueve las relaciones entre quienes participan, haciéndolas parte del proceso, disolviendo el rol de autoría del arquitecto proyectista como valor único. Promoviendo así, una arquitectura relacional y vincular que construye afectividad como parte del proceso, hacia un proyecto urbano como bien social de la comunidad que lo genera. Además, se observa que atravesar toda la investigación desde una perspectiva de género, como impulsamos desde el colectivo La Ciudad Que Resiste, plantea un modelo de gestión urbana que ubica a las personas en el centro de las decisiones, teniendo en cuenta la diversidad de experiencias y de sujetos para potenciar la vida en comunidad. El aporte y aprendizaje de esta metodología está integrada al título de este artículo. Cada palabra es parte del aprendizaje de este proceso. Y se detalla a continuación, el título es: El proyecto urbano como una experiencia...

Colectiva: toda construcción es colectiva, nadie hace nada solo (Haraway, 2019).

Colaborativa: valoramos el alcance que genera la participación barrial, el aporte de cada persona expande exponencialmente el proyecto. Nada se hace a sí mismo. Nada es autopoiético (Haraway, 2019).

Situada: la escala local permite conocer las necesidades desde cerca. Nadie vive en todas partes. Nada está conectado a todo. Todo está conectado a algo (Haraway,2019).

Performática: el hacer con el cuerpo, las caminatas, las performances artísticas en el espacio público son herramientas de transformación social (Careri, 2013).

Transdisciplinar: El conocimiento desde múltiples puntos de vista, amplía las posibilidades de diseño y deconstruye los saberes absolutos en pos de proyectos plurales e integrales.

Es importante también aclarar que los proceso comunitarios llevan mucho tiempo en su consolidación y construcción — cinco años en este caso- y los avances no son lineales, ni productivistas, ni totalmente controlables. La construcción colectiva que planteamos es en RED es múltiple y allí radica su potencia, pero a su vez requiere de muchos esfuerzos sostenidos, un trabajo sistemático y una gestión sensible; que muchas veces recae en esfuerzos autogestivos o sin recursos. Pero que podrían sentar las bases de un modelo mixto de gestión urbana para incluir en los municipios; una cogestión de los proyectos, que incluya diversidad de promotores, tanto territoriales, artísticos, arquitectónicos, de gestión urbana, de patrimonio, urbanismo ecofeminista, etc. Finalmente el aporte a la planificación participativa que queremos proponer, es una metodología para generar proyectos de ciudad, desde 
prácticas colectivas sensibles, para repensar el barrio y la ciudad en el siglo Xxi desde una perspectiva feminista. ${ }^{12}$

\section{Aclaración sobre el lenguaje inclusivo}

La lengua castellana nos enfrenta con un problema del binarismo femenino/masculino y el uso del masculino cuando en realidad se expresa una multiplicidad. En esta investigación dimos lugar a las múltiples maneras de activar el lenguaje que empiezan a expresarse con mayor fuerza en Argentina.

12 Este artículo se limita al desarrollo de la etapa en la que nos encontramos que es el anteproyecto. Para dar inicio a un proceso de transformación barrial. Queda planteado el camino entonces para desarrollar todo el proyecto ejecutivo y su materialización a escala 1:1 como modo de verificación de toda la propuesta a escala real. 


\section{Referencias bibliográficas}

Abalos, Iñaki y Herreros, Juan (1997). Áreas de impunidad. Barcelona: Editorial Actar.

Allen, Stan (2009). Mapping the unmappable: On Notation. En Allen, S. (Ed.), Practice: architecture, technique + representation (pp.41-67). Amsterdam: Routledge.

Careri, Francesco (2013). Walkscapes el andar como práctica estética. Barcelona: Gustavo Gili.

Careri, Francesco (2016). Pasear, detenerse. Barcelona: Gustavo Gili.

Col.Lectiu Punt 6 (2019). Urbanismo feminista. Por una transformación radical de los espacios de vida. Barcelona: Virus Editorial

De Certeau, Michel (1990). La invención de lo cotidiano. Paris: Gallimard.

Deleuze, Gilles y Guattari, Félix (1980). Mil mesetas. Capitalismo y Esquizofrenia. Paris: Ed. De Minuit.

Deleuze, Gilles y Guattari Félix (2002). Rizoma y otros textos. Madrid: Editora Nacional Madrid.

Greco, Alberto (1962, 29 de julio). Manifiesto Dito dell'Arte Vivo. Génova. Recuperado el 1 de abril de 2017 de: http://www.albertogreco.com/es/obras/ artevivo/manifiestodito/index.htm.

Gorelik, Adrian (2004). Miradas sobre Buenos Aires. Buenos Aires: Siglo veintiuno.

Haraway, Donna. J. (1991). Simians, Cyhorgs and Women. The Reinvention of Nature. Londres: Free Association Books.

Haraway, Donna. J. (2019). Seguir con el problema. Bilbao: Consonni. Edición original en inglés: Staying with the trouble: making kin in the Chthulucene. Durham: Duke University Press, 2016.

Hedva, Johanna (2015, 7 de Octubre). My Body Is a Prison of Pain so I Want to Leave It Like a Mystic But I Also Love It Eं Want It to Matter Politically. Women's Center for Creative Work at Human Resources, Los Angeles. Recuperado el 30 de junio de 2021 de: https://vimeo.com/144782433.
Jacobs, Jane (1961). Muerte y vida de las grandes ciudades. Nueva York: Random House.

Jáuregui, Jorge Mario (2012). Lo ético, lo estético, lo político. En Jáuregui, J.M. (Ed.), Estrategias de articulación urbana (pp.72-75). Buenos Aires: Nobuko.

La ciudad que resiste, colectiva de arquitectas (2019). La ciudad que resiste, hacia un urbanismo feminista. La Plata: Editorial Edulp.

Moisset, Inés (2015, 8 de marzo). Acerca de. [Entrada de blog] Un día | una arquitecta. Recuperado el 30 de junio de 2021 de: https:/ / undiaunaarquitecta. wordpress.com/acerca-de/.

Muxí Martínez, Zaida (2018). Mujeres, Casas y Ciudades. Más Allá del Umbral. Barcelona: PPR-barcelona.

Muxi Martínez, Zaida (2019). Ciudades cuidadoras. De las ciudades de la competencia a las ciudades de la colaboración. En Gorka Rodriguez, Olea (Ed.), Hacia una arquitectura de los cuidados (pp. 178-187). Bilbao: Urbanbat.

Navarro, Luis (1999). Internacional situacionista, vol. I: La realización del arte. Madrid: Literatura Gris.

Onfray, Michel (2000). La construcción de uno mismo. Buenos Aires: Perfil.

Palero, Santiago (2017). Arquitectura participativa. Un estudio a partir de tres autores: Turner, Habraken y Alexander (Tesis doctoral). Córdoba: Editorial de la Facultad de Arquitectura, Urbanismo y Diseño de la Universidad Nacional de Córdoba.

Rivera Cusicanqui, Silvia (2016). Sociología de la imagen. Madrid: Tinta Limón.

Taccari, Elina (2019). Extendiendo la UNLP: Centro de Formación en Oficios (Proyecto final de carrera). Facultad de Arquitectura y Urbanismo de La Plata, Argentina.

Zumthor, Peter (2006). Atmósferas. Barcelona: Gustavo Gili.

Lima, Luciana y Pastuszuk, Verónica (2021). El proyecto urbano como experiencia colectiva, colaborativa, situada, perfomática y transdisciplinar. Hábitat y Sociedad, 14, 159-183.

<https://doi.org/10.12795/HabitatySociedad.2021.i14.09> 


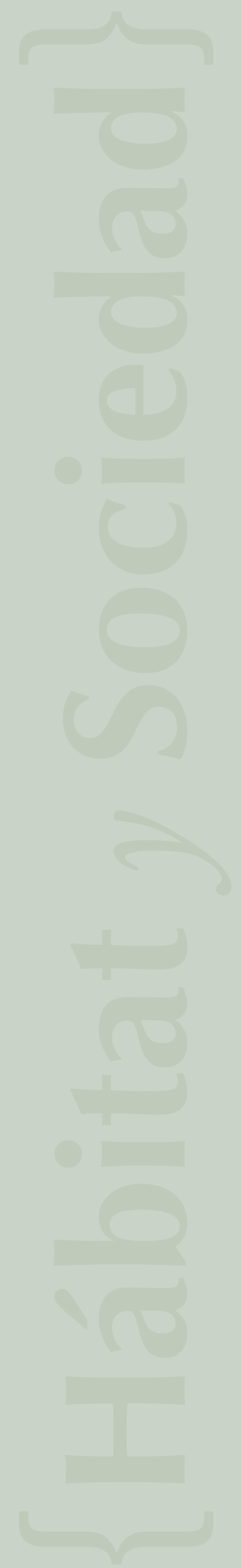

